\title{
A critical evaluation of the fish early-life stage toxicity test for engineered nanomaterials: experimental modifications and recommendations
}

Shaw, BJ

http://hdl.handle.net/10026.1/4945

10.1007/s00204-016-1734-7

Archives of Toxicology

Springer Verlag

All content in PEARL is protected by copyright law. Author manuscripts are made available in accordance with publisher policies. Please cite only the published version using the details provided on the item record or document. In the absence of an open licence (e.g. Creative Commons), permissions for further reuse of content should be sought from the publisher or author. 
A critical evaluation of the fish earlylife stage toxicity test for engineered nanomaterials: experimental modifications and recommendations

\section{Benjamin J. Shaw, Corin C. Liddle,}

\section{Kirsten M. Windeatt \& Richard}

\section{Handy}

\section{Archives of Toxicology}

ISSN 0340-5761

Arch Toxicol

DOI 10.1007/s00204-016-1734-7

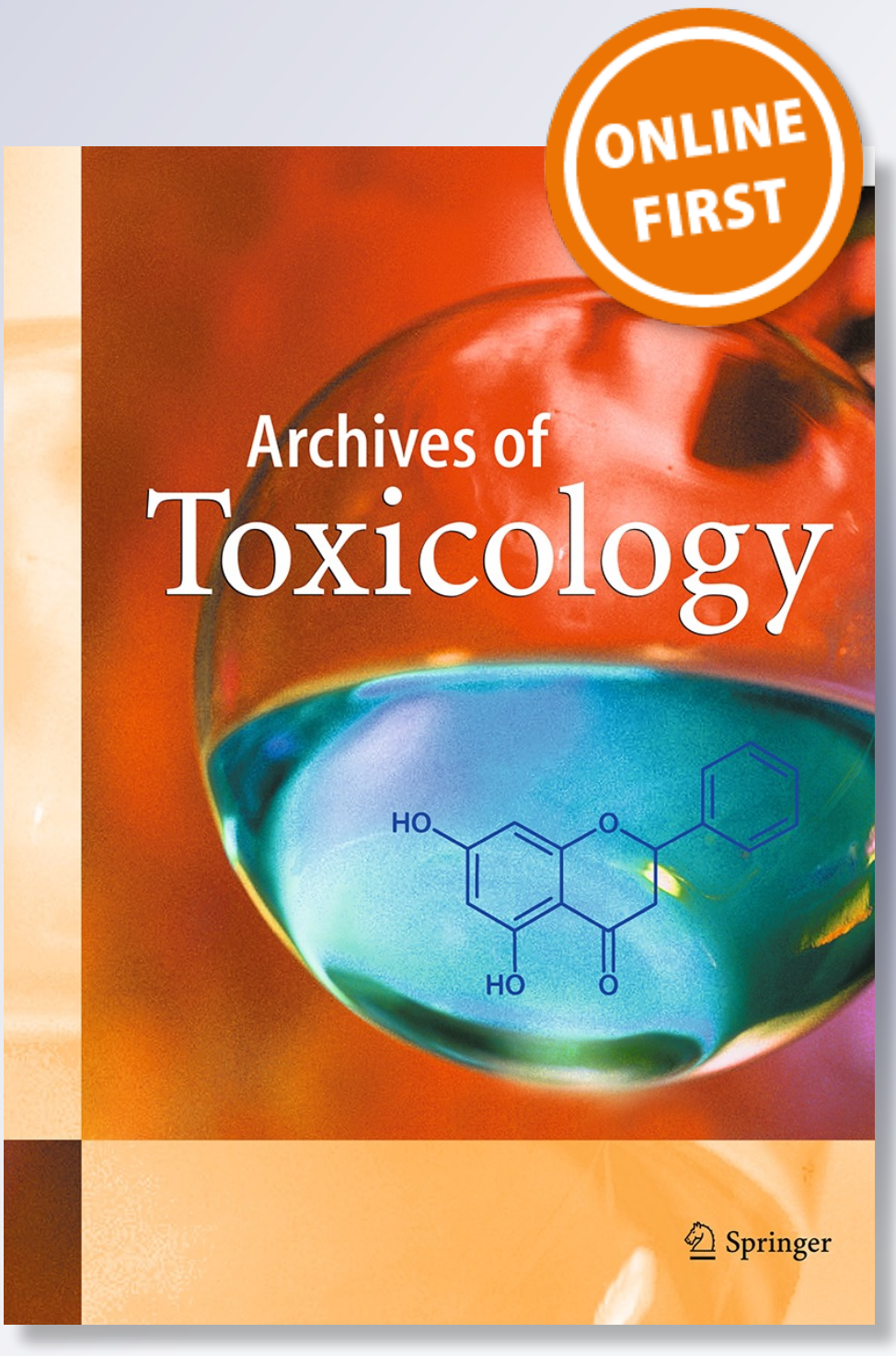

是 Springer 
Your article is protected by copyright and all rights are held exclusively by SpringerVerlag Berlin Heidelberg. This e-offprint is for personal use only and shall not be selfarchived in electronic repositories. If you wish to self-archive your article, please use the accepted manuscript version for posting on your own website. You may further deposit the accepted manuscript version in any repository, provided it is only made publicly available 12 months after official publication or later and provided acknowledgement is given to the original source of publication and a link is inserted to the published article on Springer's website. The link must be accompanied by the following text: "The final publication is available at link.springer.com". 


\title{
A critical evaluation of the fish early-life stage toxicity test for engineered nanomaterials: experimental modifications and recommendations
}

\author{
Benjamin J. Shaw ${ }^{1} \cdot$ Corin C. Liddle $^{1} \cdot$ Kirsten M. Windeatt $^{1} \cdot$ Richard D. Handy $^{1}$
}

Received: 24 March 2016 / Accepted: 28 April 2016

(C) Springer-Verlag Berlin Heidelberg 2016

\begin{abstract}
There are concerns that regulatory toxicity tests are not fit for purpose for engineered nanomaterials (ENMs) or need modifications. The aim of the current study was to evaluate the OECD 210 fish, early-life stage toxicity test for use with $\mathrm{TiO}_{2}$ ENMs, Ag ENMs, and MWCNT. Both $\mathrm{TiO}_{2}$ ENMS $\left(\leq 160 \mathrm{mg} \mathrm{l}^{-1}\right)$ and MWCNT $\left(\leq 10 \mathrm{mg} \mathrm{l}^{-1}\right)$ showed limited acute toxicity, whilst $\mathrm{Ag}$ ENMs were acutely toxic to zebrafish, though less so than $\mathrm{AgNO}_{3}$ (6-day $\mathrm{LC}_{50}$ values of 58.6 and $5.0 \mu \mathrm{g} \mathrm{l^{-1 }}$, respectively). Evidence of delayed hatching, decreased body length and increased muscle width in the tail was seen in fish exposed to Ag ENMs. Oedema (swollen yolk sacs) was also seen in fish from both Ag treatments with, for example, mean yolk sac volumes of 17,35 and $39 \mu \mathrm{m}^{3}$ for the control, $100 \mu \mathrm{g} \mathrm{l}^{-1} \mathrm{Ag}$ ENMs and $5 \mu \mathrm{g}^{-1} \mathrm{AgNO}_{3}$ treatments, respectively. Among the problems with the standard test guidelines was the inability to maintain the test solutions within $\pm 20 \%$ of nominal concentrations. Pronounced settling of the ENMs in some beakers also made it clear the fish were not being exposed to nominal concentrations. To overcome this, the exposure apparatus was modified with the addition of an exposure chamber that ensured mixing without damaging the delicate embryos/ larvae. This allowed more homogeneous ENM exposures, signified by improved measured concentrations in the beakers (up to 85.7 and $88.1 \%$ of the nominal concentrations from $10 \mathrm{mg} \mathrm{l}^{-1} \mathrm{TiO}_{2}$ and $50 \mu \mathrm{g}^{-1} \mathrm{Ag}$ ENM exposures, respectively) and reduced variance between measurements
\end{abstract}

Richard D. Handy

rhandy@plymouth.ac.uk

1 Ecotoxicology Research and Innovation Centre, School of Biological Sciences, Plymouth University, Drake Circus, Plymouth PL4 8AA, UK compared to the original method. The recommendations include: that the test is conducted using exposure chambers, the use of quantitative measurements for assessing hatching and morphometrics, and where there is increased sensitivity of larvae over embryos to conduct a shorter, larvae-only toxicity test with the ENMs.

Keywords OECD 210 regulatory toxicity test $\cdot$ Engineered nanomaterials $\cdot$ Fish $\cdot$ Silver $\cdot$ Titanium $\cdot$ Dioxide $\cdot$ Multiwalled carbon nanotubes

\section{Introduction}

Acute aquatic toxicity tests with algae, invertebrates and fish form an integral part of hazard identification for the process of environmental risk assessment (Crane et al. 2008). In the interests of the principle of mutual acceptance of data (MAD principle) by member states, the Organisation for Economic Co-operation and Development (OECD) have been instrumental in establishing the acceptance of these standardised regulatory toxicity tests. The basis of the MAD principle is that conducting a test in accordance with OECD Test Guidelines and OECD Principles of Good Laboratory Practice (GLP) should provide confidence in the data from a single study in order to avoid repetition of the experiments in each country that may use the data (Handy et al. 2012a). Other test protocols are also in use internationally with slight variations from the OECD tests, such as the fish acute toxicity test, freshwater and marine (OPPTS 850.1075, 1996), and the fish early-life stage toxicity test (EPA OPPTS 850.1400, 1996) in the USA. However, all these tests were originally designed for chemicals that either were soluble in water or could at least be put into the aqueous phase. Recently, attention has focussed on the hazard assessment of engineered 
nanomaterials (ENMs) which form dispersions rather than being soluble in water, and there are concerns that the current regulatory toxicity tests are not fit for purpose or may need modifying to work for these new materials (Handy and Shaw 2007; Handy et al. 2012a; Petersen et al. 2015).

The exact definition of an engineered nanomaterial is still being debated, but for regulatory purposes, they can be described as a material with one or more external dimensions in the size range of $1-100 \mathrm{~nm}$ and with $\geq 50 \%$ of the particles in the number size distribution in the nanoscale range (European Commission 2011). ENMs often have very different physico-chemical properties compared to their bulk or metal salt counterparts, including size, shape, specific surface area, surface charge and chemical reactivity (Handy et al. 2008; Klaine et al. 2008, 2012), and often form dispersions, not aqueous solutions in water. Depending on the water and particle chemistry, the ENM for testing may settle from the water by processes such as aggregation or agglomeration. Consequently, the handling of ENMs in regulatory toxicity tests requires careful consideration with respect to maintaining the exposure, as well as interpreting the data for hazard assessment (Crane et al. 2008; Handy et al. 2008).

Acute fish toxicity tests are required as part of the base set or first tier of regulatory hazard assessment. There are currently no specific requirements for ENMs under the European Union's Registration, Evaluation, Authorisation and Restriction of Chemicals (REACH) programme, but ENMs are considered as new substances and may require testing (see Crane et al. 2008). However, there are reports of problems when conducting unmodified aquatic tests with ENMs, including shading in algal tests (e.g., Schwab et al. 2011), difficulty in the maintenance of exposure concentrations in fish tests (e.g., Bilberg et al. 2010; Christen et al. 2013) and concerns about the suitability of test endpoints for ENMs (e.g., mortality, growth rate, reproduction, Crane et al. 2008; Handy et al. 2012a, b). Nonetheless, several researchers have reported both the lethal and sublethal effects of ENMs to fish and other aquatic life during routine ecotoxicological experiments, albeit with some of the difficulties outlined above (e.g., Ag ENMs in medaka, Chae et al. 2009; Cu ENMs in zebrafish, Griffitt et al. 2007; Ag, $\mathrm{Cu}, \mathrm{Al}, \mathrm{Ni}, \mathrm{Co}$ and $\mathrm{TiO}_{2}$ ENMs to zebrafish, daphnids, and algae, Griffitt et al. 2008; Cu ENMs to rainbow trout, Shaw et al. 2012; Au ENMs in zebrafish, Truong et al. 2012).

In 1992, the OECD 210 fish, early-life stage toxicity test (OECD 1992a) was adopted following a proposal in 1988 (OECD 2013) and was one of the first regulatory toxicity tests to use fish embryos for a variety of chemicals. The test includes different life stages from recently fertilised embryos up to 30 days post-hatching for zebrafish and as long as 60 days post-hatching for rainbow trout (OECD 2013). Although the early-life stage (ELS) test is being used for evaluating the hazard of metals and organic chemicals to fishes, it remains to be seen if the test is sensitive for ENMs, which life stage is most appropriate for testing, and whether or not the exposures can be conducted reliably with dispersed materials.

The primary aim of the current work was to initially test selected ENMs with different chemistries using the current OECD 210 fish, early-life stage toxicity test for its suitability for use with these materials, and then, to critically evaluate the test results and procedures at the bench, suggesting improvements or modifications to the test protocol where required for ENMs. Although this work focused on one particular test, large parts of the results are pertinent to other fish tests (e.g., OECD 1992b, 1998). A case study approach was adopted whereby three ENMs with different toxicities and chemistries were tested. The ENMs were obtained from the European Commission Joint Research Centre (JRC, Ispra, Italy). Titanium dioxide ENMs were chosen because this material has shown low acute toxicity in previous studies with fish (e.g., Federici et al. 2007; Zhu et al. 2008; Clemente et al. 2013; Ramsden et al. 2013), and limited free metal ion dissolution (Rasmussen et al. 2014a), whilst silver ENMs were chosen as a material where acute toxicity to fish is a concern (e.g., Asharani et al. 2008; Bilberg et al. 2012; Kwok et al. 2012; Ribeiro et al. 2014), and depending on the water chemistry, Ag ENMs may show some dissolution of the toxic $\mathrm{Ag}^{+}$ion (Mitrano et al. 2014). Finally, multi-walled carbon nanotubes (MWCNT) were chosen in order to assess differences due to shape and structure. The specific objectives were to evaluate the problems and limitations of the ELS test using zebrafish (Danio rerio), to compare the utility of lethal and sublethal endpoints proposed in the original test protocol for ENMs, and to identify any ambiguity in the original test protocol that may introduce variability into the test method or results for ENMs. Given the concerns about the sensitivity of different life stages of fishes to chemicals, the case studies also evaluated whether it was appropriate to continue using both embryo and larval stages consecutively in the OECD test, or whether the test could be shortened to one sensitive life stage. Modifications of the test method and apparatus were also explored to improve the maintenance of the exposure concentrations in the test when using ENMs. Finally, having critically evaluated the results and test protocols, firm recommendations are made on how the OCED test should be modified for regulatory use with ENMs.

\section{Is the current, unmodified, OECD 210 test fit for purpose for use with ENMs?}

The current work was carried out using the original OECD TG (1992a), but these guidelines were updated shortly after the experimental work was finished (OECD 2013). However, the fundamental principles and experimental design are almost identical between the two versions of the test, 
and so, the work remains valid. All of the points below relate to the current, 2013, version of the TG. The first experimental step was to assess the OECD 210 fish, earlylife stage toxicity test for use with $\mathrm{TiO}_{2}$ ENMs, Ag ENMs and MWCNT at the bench, i.e., without modifications for ENMs, and to follow the written protocol as closely as possible. However, even before commencing the laboratory work, it became apparent that the text of the protocol had some ambiguity in places which allowed small deviations that might be important with ENMs in mind. Regardless of ENMs, there were also some concerns from the perspective of fish biology about the purpose and utility of the test description. Many of these ambiguities of the text were carried over into the 2013 updated TG, and some of the concerns about the wording of the current protocol are outlined below.

According to OECD 210 TG (OECD 2013), the aim of the test is to: ... define the lethal and sub-lethal effects of chemicals on the stages and species tested. They yield information of value for the estimation of the chronic lethal and sub-lethal effects of the chemical on other fish species. The notion of chronic sublethal effects is immediately problematic for ENMs, the test, whether considered as a time proportion of the life expectancy of a zebrafish or in terms of absolute time duration is an acute (short term) test, and cannot yield information on chronic effects. Unlike existing chemicals, there are also insufficient data on ENMs to extrapolate acute toxicity estimates to chronic effects. In addition, apart from mortality or survival, the only other biological endpoints in the test are hatching success, abnormal appearance (morphological abnormalities), abnormal behaviour and body weight and length. For the abnormal appearance, the TG gives no specific guidance on how to make such morphometric measurements or what exactly to measure.

In terms of dosing the beakers or vessels with the test chemical, the TG states that: The test system should preferably be conditioned with concentrations of the test chemical for a sufficient duration to demonstrate stable exposure concentrations prior to the introduction of test organisms. However, it is currently unknown whether this is a valid approach with ENMs. The length of time before the fish are added could be critical with some ENMs known to quickly precipitate out of the water column. Also, the ecological relevance of the dosing method should be considered. For example, in the wild, a polluted effluent would be added to the fish already in the water, not vice versa. This is most pertinent with embryos where the time to dose (with or without the animals present) would either result in the embryos being placed on top of precipitated ENMs or beneath them, with potential consequences to subsequent toxicity.

The OECD 210 TG states that the ... concentrations of the test chemical higher than the $96 \mathrm{hLC} C_{50}$ or $10 \mathrm{mgl}^{-1}$, whichever is the lower, need not be tested... However, from previous experiments within our laboratory, it was clear that this concentration was too low to elicit a toxicological response for some ENMs. Therefore, the upper concentration for all subsequent $\mathrm{TiO}_{2}$ ENM experiments was increased (see below). The TG suggestion of using $\mathrm{LC}_{50}$ values for guidance on where to set the highest concentration in the test was also less useful. Of course, range finding studies can be attempted, but for many ENMs, the practical problems of dispersing high $\mathrm{mg}$ or $\mathrm{g}$ concentrations of ENMs in water has so far prevented the precise or reliable determination of exact $\mathrm{LC}_{50}$ values for fishes (Handy et al. 2011, 2012a). The OECD 210 TG also stipulates that: Normally five concentrations of the test chemical, with a minimum of four replicates per concentration, spaced by a constant factor not exceeding 3.2 are required. However, these aspects of the TG present two issues. Firstly, for ENMs, it is still not clear if mass concentration is the best metric to describe toxicity data, and secondly, the spacing factor of 3.2 has not been validated for ENMs. Furthermore, whether in a range finding experiment, or the main test, the data will be a composite of both embryo and larval stages. From the perspective of fish biology, this is illogical, given that the toxicity of chemicals to fish embryos and larvae may be very different (e.g., Eaton et al. 1978; McKim et al. 1978a, b; Ma and Diamond 2013), and from the perspective of ENMs, which life stage represents the "sensitive window of toxicity" during development is not yet established.

Finally, the OECD 210 TG stipulates that: ... the analytical measure of the test concentrations is compulsory. However, there are currently no routine methods with which to accurately quantify ENMs in solution. The metallic component of metal-based ENMs can be assessed using analytical techniques such as ICP-MS, but several problems exist when doing so (Shaw et al. 2013). Engineered nanomaterials such as carbon nanotubes are also problematic to quantify as there is currently no way to differentiate between these particles and background carbon from other sources. Also, for ENMs such as cadmium telluride quantum dots (QD), there is no routine method to quantify the intact material with respect to stoichiometry of the component substances. Analytical methods such ICP-MS can determine cadmium and tellurium concentrations in the water samples or animals, but these do not necessarily inform on the state of the composite QD. The TG goes on to state: Prior to initiation of the exposure period, proper function of the chemical delivery system across all replicates should be ensured (for example, by measuring test concentrations). Analytical methods required should be established, including an appropriate limit of quantification (LOQ) and sufficient knowledge on the substance stability in the test system. Again, current analytical instruments and techniques are often inadequate and modifications, or 
new methodologies are still being developed. Lastly, with respect to measured concentrations of the test chemical the TG state that: When the measured concentrations do not remain within 80-120\% of the nominal concentration, the effect concentrations should be determined and... expressed relative to the geometric mean of the measured concentrations for semi-static tests (see Chapter 5 in the OECD Guidance Document No. 23 on aquatic toxicity testing of difficult substances and mixtures... For traditional chemicals, the notion is to use nominal concentrations to simplifying the logistics and cost, unless there is a clear reason for more detailed quantification. The complex behaviour and settling of ENMs will always require the latter.

The only notable difference in experimental design between the original $1992 \mathrm{TG}$ and the updated $2013 \mathrm{TG}$ is that they now state that there should be a minimum of four replicates, but in the current work, a triplicate design was used as per the original protocol. Throughout this study, ELS zebrafish were exposed to nominal concentrations of either $\mathrm{TiO}_{2}$ ENMs (NM-105), $\mathrm{TiO}_{2}$ bulk (NM-100), Ag ENMs (NM-300K), $\mathrm{AgNO}_{3}$, MWCNT (MN-400) or carbon black (CB) (Table 1). A dispersant control was also utilised in the Ag ENM experiments (NM-300K-Dis). Here, fish were exposed to a dispersant concentration equivalent to that in the highest Ag ENM or MWCNT treatment, respectively (Table 1). See below for ENM characterisation.

Brood stocks of adult wild Indian karyotype zebrafish (Danio rerio) were kept at Plymouth University in 20-1 aerated, flow-through glass aquaria containing dechlorinated Plymouth tap water. Temperature was maintained at $28{ }^{\circ} \mathrm{C}$, and the photoperiod was $14 \mathrm{~h}$ light/10 h dark (with an identical temperature and photoperiod used during all experiments). Following fertilisation, the embryos were cleaned (i.e., removal of debris and unfertilised eggs) and viable embryos randomly selected and placed into 500-ml experimental Pyrex beakers (Fisher Scientific, UK; $n=20$ embryos per beaker, 60 per treatment) containing $400 \mathrm{ml}$ dechlorinated Plymouth tap water (buffered to circumneutral $\mathrm{pH})$. The TG does not stipulate that a synthetic water should be used, only that: Any water in which the test species shows suitable long-term survival and growth may be used as test water (see Annex 4). It should be of constant quality during the period of the test. The utility of the tap water at Plymouth University has consistently been suitable for fish husbandry purposes with little change in chemistry over time. OECD $210 \mathrm{TG}$ indicates the exposure should continue until all of the control fish are feeding exogenously and the control fish reach a juvenile stage (up to 30 days for zebrafish) (temperature quoted as $26 \pm 1.5^{\circ} \mathrm{C}$ ). Regardless of nano, it is not clear why degree-days are not used as the unit of time of development in the OECD test, so that data can be compared with the scientific literature on fish biology. Nonetheless, in the current experiments, embryos were exposed to the nominal concentrations (as above) of each ENM or appropriate control until 6 day post-fertilisation. This duration allowed the collection of the data required to investigate the overall aims of the work, and involved both the unhatched embryos and the hatched larvae, but also minimised the incursion of the experiments into first feeding where the fish would be considered "freeliving vertebrates" from the perspective of animal welfare legislation. Furthermore, conducting the exposure past this point in the life stage would require the feeding of the larvae, and introduce a confounding factor of ENM adsorption to food pellets, or indeed, particulate material from the food inevitably entering the water.

The exposures were carried out using a semi-static regime (100\% water renewal every $24 \mathrm{~h}$ with subsequent redosing). The unmodified TG states that: ... (at least two thirds) of the test solution/control volume is changed... In the current experiments, initial attempts at $80 \%$ daily water changes with the ENMs present in the test vessels were unsuccessful. Because of particle settling, the remaining $20 \%$ of the water in each beaker contained a disproportionate concentration of ENMs (data not shown). Therefore, to ensure accurate dosing and test water renewal, $100 \%$ water changes were carried out in all subsequent experiments. To accomplish this, new test solutions were prepared in clean beakers and the embryos or larvae were transferred with subsequent redosing as described in the TG.

\section{Nanoparticle stock preparation and characterisation}

The OECD $210 \mathrm{TG}$ is intended for use with many different chemical substances, and unsurprisingly it would be impractical to document methods for dissolving or dispersing test chemicals. Instead, the TG indicates: ... evidence that the measurements [of expected nominal] refer to the concentrations of the test chemical in true solution... Currently, there are not many validated methods for determining ENM concentrations in water (von der Kammer et al. 2012), and it is accepted that particle size distribution measurements can be problematic in natural waters (Ranville and Montano 2015). Nonetheless, preliminary guidance on ENM characterisation and dispersion from the Working Party on Nanomaterials (WPMN) is in preparation, and some guidance on stock preparation and dosing is already available (OECD 2012). It is therefore prudent to consider these nano-specific guidance notes as supplementary information that can inform on the preparations for running the OECD 210 method specifically with ENMs. The OECD 210 TG states that: The use of a solvent carrier is not recommended.... but is allowable where necessary. For ENMs at least, it may be preferable to avoid dispersing agents where possible, and if they must be used to 


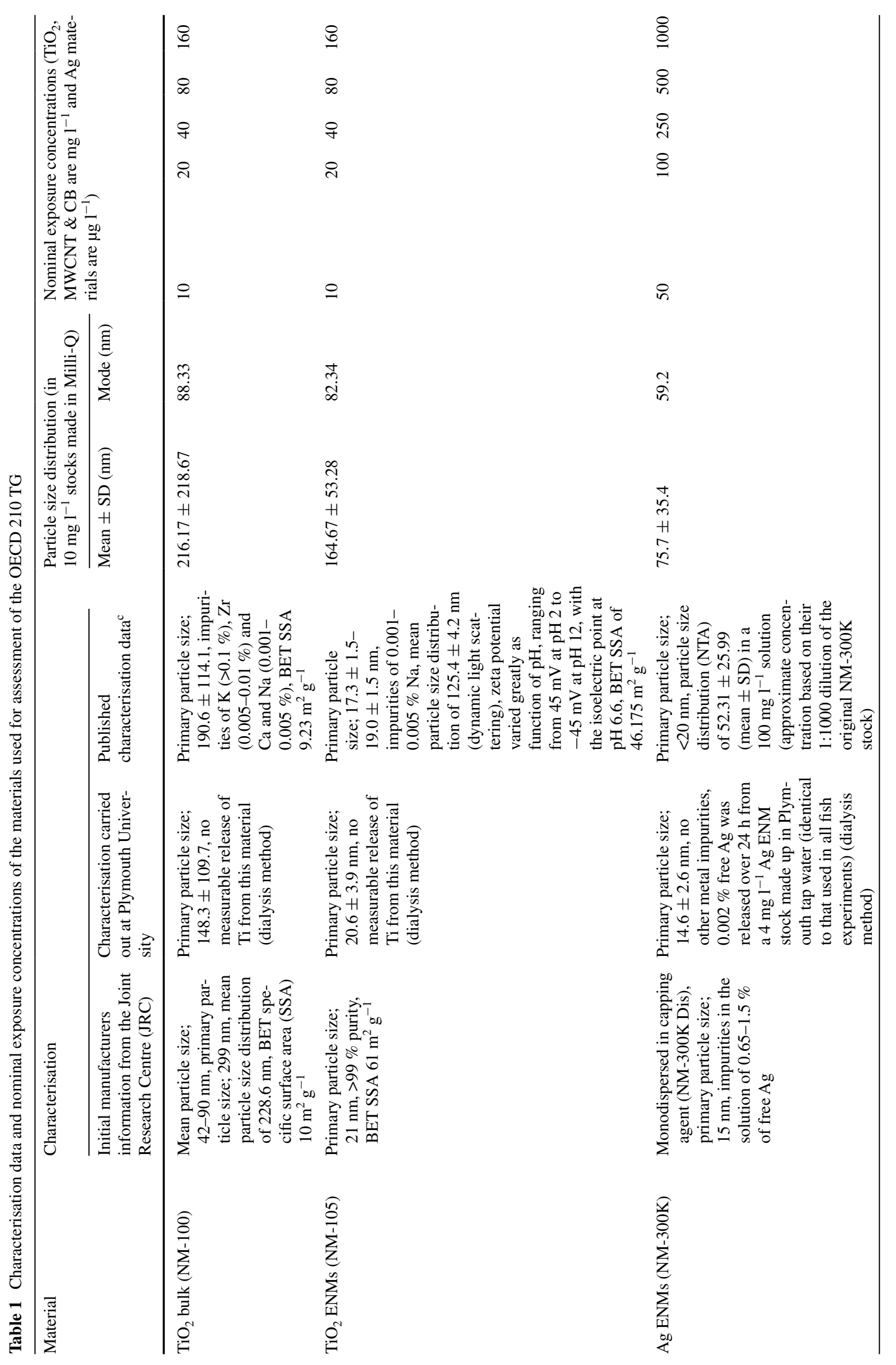




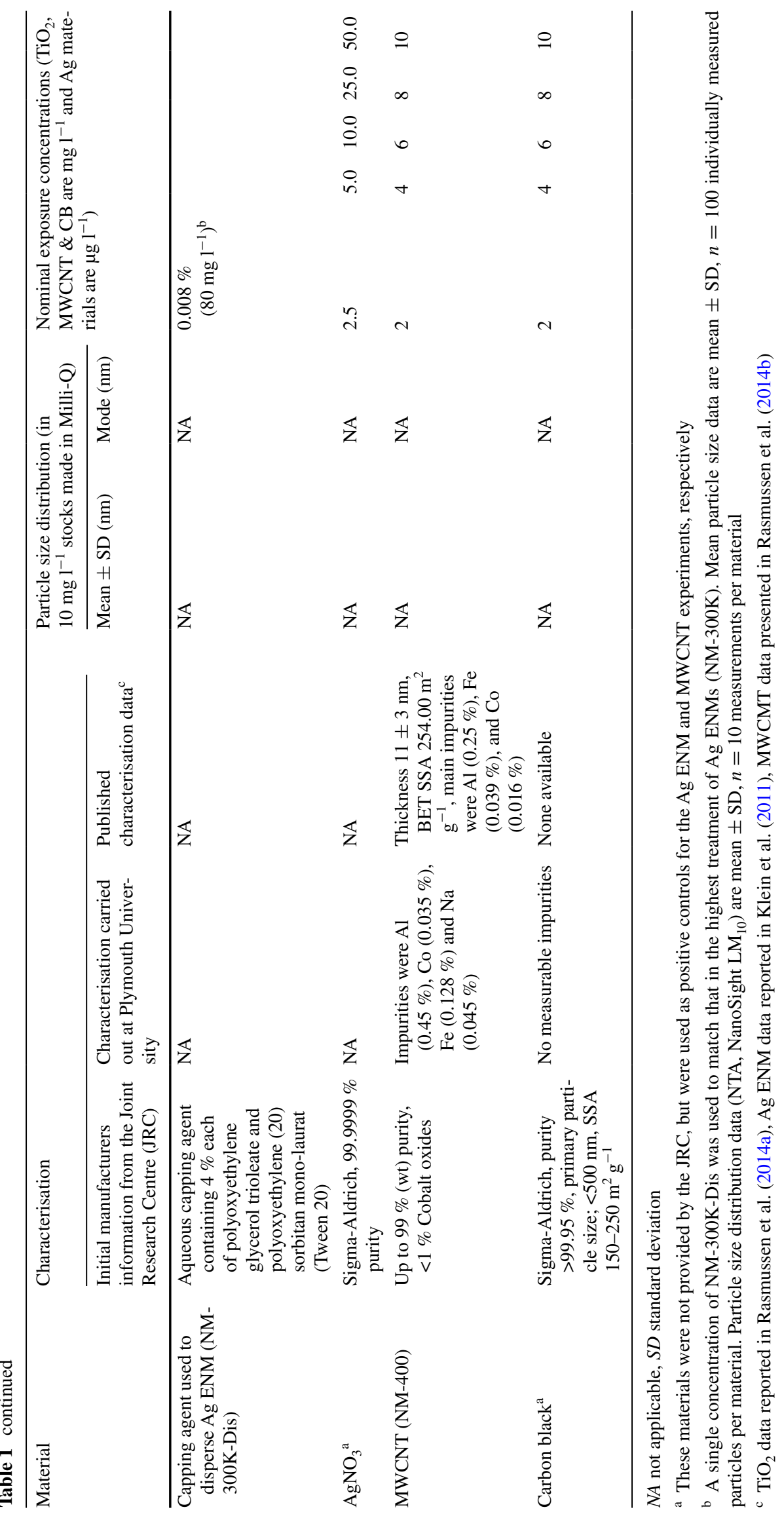


be mindful of the ratio of dispersant concentration: ENM concentration, and its potential effects on particle shape, coating or reactivity (Handy et al. 2012a, b). The OECD 210 TG directs the reader to the OECD guidance document on the aquatic toxicity testing of difficult substances and mixtures (OECD 2000) for further information when using a solvent in testing. However, this document was not written with ENMs in mind, and there are no provisions in the guidance notes for ENMs, though the document does state that the nature of the difficulty in testing colloids is achieving, maintaining and measuring exposure concentrations, which clearly applies to ENMs. Both the OECD 210 TG (OECD 2013) and the difficult substances and mixtures document (OECD 2000) recommend a maximum solvent concentration of $100 \mu \mathrm{ll}^{-1}$ in order to avoid effects from the substance used. Again, this approach has not been validated for ENMs.

In the current study, ENM stocks were produced using our standard laboratory protocol (e.g., Federici et al. 2007; Shaw et al. 2012, 2013). Briefly, all glassware was acidwashed and triple-rinsed in deionised water. The desired mass of powder was carefully weighed out for $\mathrm{TiO}_{2}$ ENMs and MWCNT, and volume accurately pipetted for $\mathrm{Ag}$ ENMs and then added to a volumetric flask containing $200 \mathrm{ml}$ ultrapure water (Milli-Q, 18.2 M 2 -cm resistivity, ion free and unbuffered). Following manual mixing and inversion, the stocks were then quickly decanted into glass bottles (Fisherbrand, borosilicate glass with polypropylene cap). The stocks $(200 \mathrm{ml})$ were immediately sonicated for $6 \mathrm{~h}$ (bath type sonicator, 35-kHz frequency, Fisherbrand FB 11010 , Germany) and a further hour prior to each dosing event along with manual agitation (shaking and swirling). Note that Ag ENM stocks were freshly prepared each day in order to minimise the risk of silver ion dissolution from the ENMs. Stocks of $\mathrm{TiO}_{2}$ bulk, carbon black (CB) and $\mathrm{AgNO}_{3}$ were prepared precisely as above for ENMs, but with stirring for $2 \mathrm{~h}$ initially and a further $1 \mathrm{~h}$ prior to dosing replacing sonication (magnetic stirrer IKA-Werke RET basic $\mathrm{C}$, at $300 \mathrm{rpm}$ ). Both the $\mathrm{Ag}$ ENMs and the $\mathrm{AgNO}_{3}$ stocks were stored in dark bottles throughout.

Characterisation of the ENMs used in the current study was conducted in our laboratory, whilst initial JRC characterisation data were provided with the materials (Table 1). Furthermore, extensive characterisation of these materials was carried out in separate studies incorporating several laboratories and published as part of the European Commissions' JRC Science and Policy Reports (i.e., Rasmussen et al. 2014a for $\mathrm{TiO}_{2}$ materials, Rasmussen et al. 2014a, b for MWCNT and Klein et al. 2011 for Ag ENMs) (data presented in Table 1).

The primary particle size of the ENMs used here was calculated by firstly imaging the particles by transmission electron microscopy (TEM, JEOL 1200EXII) and then using Image $\mathbf{J}$ Software to measure the particles on the TEM micrographs. A total of 100 particles from 10 different TEM grids were assessed per material. Further size data were generated at Plymouth University by nanoparticle tracking analysis (NTA, NanoSight $\mathrm{LM}_{10}$ ), which allows an assessment of the particle size distribution in solution. Briefly, ENM stocks were prepared at $100 \mathrm{mg} \mathrm{l}^{-1}$ (optimum ENM concentration for this technique) in Milli-Q water and sonicated for $1 \mathrm{~h}$ prior to analysis. Five subsamples of each stock were measured in duplicate giving a total of ten analyses per material. The presence of natural colloids in the water and the relatively low concentrations of ENMs used in the exposures prevented the accurate assessment of particle size distribution of the dosed, experimental waters.

\section{Assessing the dissolution of ENMs}

To better understand the mechanisms of toxicity from ENMs it is important to establish whether dissolved ions contribute to the effects. Therefore, experiments were carried out to ascertain whether ions were released from the $\mathrm{TiO}_{2}$ and Ag ENMs used in the fish exposures. These experiments used the dialysis approach as described in Besinis et al. (2014) and Al-Jubory and Handy (2013) with minor modifications. Briefly, $100 \mathrm{mg}^{-1}$ dispersions of each ENM were prepared in both Milli-Q and dechlorinated Plymouth tap water. All glassware and dialysis tubing used in the experiments were acid-washed $\left(5 \% \mathrm{HNO}_{3}\right)$ and triple-rinsed in deionised (Milli-Q) water. Dialysis bags were prepared from dialysis tubing (Sigma-Aldrich, cellulose membrane with a molecular weight cut-off at 12,000 Da) precisely as described in Besinis et al. (2014). Experiments were carried out in triplicate with each bag filled with $8 \mathrm{ml}$ of the appropriate ENM solution and secured with mediclips. The bags were then transferred to beakers containing a magnetic stirring bar and $492 \mathrm{ml}$ of the appropriate media (Milli-Q or dechlorinated Plymouth tap water), and placed onto a multipoint magnetic stirrer (RO 15P power, IKAWerke) for $24 \mathrm{~h}$ at room temperature. Water samples $(3 \mathrm{ml})$ were taken immediately and then at $24 \mathrm{~h}$, and Ti or Ag content was assessed by ICP-OES. These experiments showed minimal dissolution of $\mathrm{Ag}$ from the Ag ENM, whilst the $\mathrm{TiO}_{2}$ ENMs were stable in solution (no measurable release of Ti) (Table 1).

\section{Water quality}

The current OECD 210 TG has quality criteria that specify the allowable deviations in water chemistry within a valid test. Dissolved oxygen must be maintained over $60 \%$ of the air saturation, and water temperature must not differ by more than $\pm 1.5^{\circ} \mathrm{C}$ between test chambers or between successive days. Furthermore, the water used should be: any 
water in which the test species shows suitable long-term survival and growth... and be of constant quality during the period of the test. The guidance on water quality has its origins in historic experimental work on the physiology of fishes and the requirements for fish health. For example, the range for dissolved oxygen is intended to generally avoid a hypoxia-driven hyperventilation (e.g., Holeton and Randall 1967) that might otherwise alter the exposure dose over the gills of teleost fishes. The primary consideration for water quality measurements was not intended to be in relation to the test substance per se. Nonetheless, it remains good practice to confirm the general water quality during a test, and for ENMs, we have yet to confirm their reactive chemistries and how they might (or might not) alter the freshwater. For example, one theoretical concern for a high surface area of a negatively charged ENM might be cation depletion of the freshwater (by adsorption to the particles) leading to osmoregulatory distress. Such possibilities in data interpretation can be verified only if the composition of the water is monitored during the test.

In order to assess water quality parameters in the current study with ENMs, water samples were taken every $24 \mathrm{~h}$ (immediately prior to each water change) for $\mathrm{pH}$, dissolved and saturated oxygen, and temperature (HACH HZ40d multimeter). Separate samples were also collected for trace element analysis to inform on the general water quality and to confirm the exposure (see below). Six beakers were also randomly chosen each day and tested for total ammonia (HACH LANGE GMBH LCK kit 304 read on a HACH LANGE GmbH DR 2800 spectrophotometer). Most water quality parameters were maintained within the limits set out in the OECD 210 TG for zebrafish and thus met the validity criteria. As there were no significant differences throughout in routine water quality measurements between beakers or treatments (ANOVA, $P>0.05$ ), data were pooled by experiment. For example, water quality parameters in the first OECD 210 experiment were (mean $\pm \mathrm{SD}, n=126$ ) dissolved oxygen $\left(7.20 \pm 0.10 \mathrm{mg} \mathrm{l}^{-1}\right)$, saturated oxygen $(94.97 \pm 0.90 \%)$, $\mathrm{pH}(7.29 \pm 0.09)$ and temperature $\left(27.13 \pm 0.29^{\circ} \mathrm{C}\right)$. Total ammonia was $0.06 \pm 0.007 \mathrm{mg}^{-1}(n=36)$. The trace element profile of the water was (mean data \pm SD, $n=204$ samples) $5.97 \pm 0.70,0.77 \pm 0.30$ and $15.73 \pm 2.20 \mathrm{mg} \mathrm{l}^{-1}$ for $\mathrm{Na}^{+}, \mathrm{K}^{+}$and $\mathrm{Ca}^{2+}$, respectively, whilst total hardness $\left(\right.$ as $\mathrm{CaCO}_{2}$ ) was $42.5 \pm 5.82 \mathrm{mg} \mathrm{l}^{-1}$. The only aspects of the water chemistry that did not meet the OECD $210 \mathrm{TG}$ requirements were the $\mathrm{Cu}$ and $\mathrm{Zn}$ concentrations. The $\mathrm{Cu}$ and $\mathrm{Zn}$ levels were $6.42 \pm 4.36 \mu \mathrm{g} \mathrm{l}^{-1}$ and $7.91 \pm 6.23 \mu \mathrm{g}^{-1}$, respectively (mean $\pm \mathrm{SD}$ ), but Annex 4 of the TG states that an acceptable (limit) concentration is $1 \mu \mathrm{g} \mathrm{l}^{-1}$ for both elements. This seems an unusually low concentration to stipulate and difficult to achieve without using reconstituted water (which may have its own inherent problems), though there is no caveat that the test will be invalidated if exceeded.

\section{Confirmation of exposure}

The current OECD 210 TG does not have a detailed protocol for taking and analysing water samples to confirm exposure concentrations in the test vessels apart from: ... the concentrations of the test chemical are determined at regular intervals to characterise exposure. A minimum of five determinations is necessary. However, this may not be suitable for ENMs. The TG are intended for many different chemicals, so the absence of specific protocols for analytical chemistry is not surprising, and suggestions are given elsewhere on how frequently to measure ENM concentration and what might reasonably be achieved in aquatic tests (Handy et al. 2012a, b; Petersen et al. 2015). Nonetheless, it would be useful to develop a separate guidance document on this for ENMs, with a similar philosophy to that for organic chemicals that proved difficult to dissolve or handle in aqueous solution (e.g., guidance notes from the US EPA or OECD on difficult substances, OECD 2000).

For all experiments in the current work, water samples were taken daily from the middle of the water column of each beaker $10 \mathrm{~min}$ post-dosing and $10 \mathrm{~min}$ prior to the water change in order to confirm the 24-h exposure profile (i.e., the time period between water changes). Briefly, $10 \mathrm{ml}$ samples were acidified with $200 \mu \mathrm{l}$ of concentrated analytical-reagent-grade nitric acid (Fisher Scientific) and stored in the dark until required. All ENM samples were sonicated for $20 \mathrm{~min}$ and then vortexed for $10 \mathrm{~s}$ immediately prior to analysis (samples from the metal salt treatments were vortexed only). Inductively, couple plasma optical emission spectrometry (ICP-OES, Varian 725 ES) was used to analyse all $\mathrm{TiO}_{2}$ and $\mathrm{Ag}$ ENM samples, whilst $\mathrm{AgNO}_{3}$ samples were analysed by inductively couple plasma mass spectrometry (ICP-MS, Thermo Fisher Scientific X Series 2) with calibration and quality control as described in Shaw et al. (2013). Briefly, instrument calibration was achieved by using matrix-matched ICP standard prepared from Arista ${ }^{\circledR}$ plasma emission grade Ti and Ag solutions. All samples for ICP-MS also had internal standards (1\% indium and $1 \%$ iridium) to assess instrument drift during the analyses. For $\mathrm{TiO}_{2}$ analysis, the ICP-OES measures Ti metal only so $\mathrm{TiO}_{2}$ values were calculated using stoichiometric conversion based on atomic weight. Data are presented as routine metric concentration units (e.g., $\mu g \mathrm{l}^{-1}$ ) or as measured percentage of the nominal dose.

\section{Measuring the biological endpoints of OECD 210}

The current OECD $210 \mathrm{TG}$ aims to assess both the lethal and sublethal effects of the test substance, with observations 
on survival and hatching made at least once daily. There are no specific instructions on the methods to be used to measure effects on fish embryos in the current OECD 210 TG. The observations should include: the stage of embryonic development, hatching and survival, abnormal appearance, abnormal behaviour, weight and body length. Criteria for death are generally well defined in the TG, but from the perspective of fish biology, the other endpoints are not. This lack of technical detail is unfortunate, and for example, references could be made to agreed anatomical/zoological descriptions of the stages of development of each species of fish so that stage of development in the test is accurately recorded the same way in different laboratories performing the test. Relevant articles on zebrafish anatomy and development are available (e.g., Laale 1977; Kimmel et al. 1995; Schilling 2002; Bird and Mabee 2003; Parichy et al. 2009; Menke et al. 2011; Bryson-Richardson et al. 2012). There is also no guidance on preserving ELS fish so that morphometrics, etc., may be done after the exposure is conducted. From the view point of ENMs, it is a question of whether these observations in the test are possible or not (the experiments below indicate the separate issue of sensitivity).

In situ observations of mortality and behaviour may be hindered by turbidity in the test solutions for some ENMs. This was evident in the current study where high mg concentrations of $\mathrm{TiO}_{2}$ gave the water a cloudy, milky appearance. For these beakers, it was necessary to decant most of the exposure medium out of the beaker in order to view and count the animals. Beakers with lower concentrations of $\mathrm{TiO}_{2}$ ENM as well as those containing Ag ENMs and MWCNT did not experience this turbidity, and therefore, the guidelines to assess mortality/survival were used throughout without problem. Each beaker was observed daily to note any abnormal swimming behaviour including lethargy, loss of equilibrium, unusual positioning in the water column (e.g., vertically positioned), lack of reaction to mechanical stimuli and avoidance behaviour (the latter characterised by increased swimming speed and/or attempting to escape). The numbers of survivors and hatched larvae were then recorded immediately prior to the water change. At the end of the exposure (day 6), remaining larvae were preserved to assess for any effects to development. The following outlines how our laboratory makes morphometric measurements on zebrafish, based on many years of experience of fish anatomy, and might be a useful addition to the current OECD TG 210 document. Briefly, larvae were terminally anaesthetised with buffered tricaine methanesulfonate (MS222) and then fixed in formalin until required for morphometric analysis. Larvae $(n=4$ per beaker, 12 per treatment where sufficient numbers remained) were photographed at the same orientation (Meiji binocular microscope with Infinity 2-2C camera). Image J software
$(1.45 \mathrm{~s})$ was the used to assess total length (from anterior part of the head to the end of the tail) as described in OECD 210 TG, skeletal muscle block width on the tail and yolk sac volume. For muscle block width, the larvae were positioned laterally and the muscle (myotomes) in the tail section (between the dorsal and ventral dermis, including the notochord) measured immediately posterior to the yolk sac (at the thickest portion of the tail). Yolk sac volumes (YSV) were calculated according to Velasco-Santamaría et al. (2011) using the equation:

$\mathrm{YSV}=\frac{\pi}{6} \times L \times H^{2}$

where $\pi(\mathrm{Pi})$ is $3.1416, L$ represents the yolk sac length (mm), and $H$ represents the yolk sac height (mm), expressed as $\mathrm{mm}^{3}$. Microscopic observations were also made in order to assess for spinal deformities (e.g., lordosis, kyphosis) and abnormal eye positioning and development. However, a lack of deformity in the spinal column and eyes of larvae from all treatments meant that there was no quantitative assessment for these endpoints.

\section{Statistical analysis}

All data were analysed by StatGraphics Centurion XVI.I. Where no beaker (test vessel) differences were observed, data were pooled by treatment for statistical analysis. After checking kurtosis, skewedness and unequal variance (Bartlett's test), data were tested for treatment, time, and treatment $\times$ time interaction effects by multifactor ANOVA followed by Fisher's $95 \%$ least-squares difference (LSD) post hoc test. When a statistically significant effect was indicated by this model, a one-way ANOVA was employed for parametric data to assess for simple effects with Fishers LSD used to locate the differences. Where the data was nonparametric, the Kruskal-Wallis test was used and differences located by notched box and whisker plots. Differences among groups were considered significant at $P<0.05$. Coefficient of variation $(\mathrm{CV})$ was calculated by $\mathrm{CV}(\%)=\left(\frac{\sigma}{\mu}\right) \times 100$, where $\sigma$ is the standard deviation and $\mu$ is the mean.

\section{Experimental case study results}

Hatching and survival of the control animals met the validity criteria set out for zebrafish in OECD 210 throughout all experiments (i.e., $70 \%$ hatching success and $75 \%$ posthatch success for zebrafish). The median lethal concentration that kills $50 \%$ of the population $\left(\mathrm{LC}_{50}\right)$ was calculated where possible, and these data are presented along with the no observed effect concentrations (NOEC) for each material in Table 2. 
Table 2 The 96 and $144 \mathrm{~h}$ lethal concentration $\left(\mathrm{LC}_{50}\right)$ and no observed effect concentration (NOEC) values of early-life stage zebrafish exposed to ENMs and relevant controls according to OECD 210

\begin{tabular}{llllll}
\hline Material & Concentration units & $96 \mathrm{~h} \mathrm{LC}_{50}$ & $144 \mathrm{~h} \mathrm{LC}_{50}$ & $96 \mathrm{~h} \mathrm{NOEC}$ & 144 h NOEC \\
\hline $\mathrm{TiO}_{2}$ Bulk (NM-100) & $\left(\mathrm{mg} \mathrm{l}^{-1}\right)$ & $>160$ & $>160$ & $<10$ & $<10$ \\
$\mathrm{TiO}_{2}$ ENMs (NM-105) & $\left(\mathrm{mg} \mathrm{l}^{-1}\right)$ & $>100$ & $>100$ & $<10$ & $<10$ \\
$\mathrm{Ag} \mathrm{ENMs} \mathrm{(NM-300K)}$ & $\left(\mu \mathrm{g} \mathrm{l}^{-1}\right)$ & 137.2 & 58.6 & 23.1 & 3.9 \\
$\mathrm{AgNO}_{3}$ & $\left(\mu \mathrm{g} \mathrm{l}^{-1}\right)$ & 6.05 & 5.0 & $<2.5$ & $<2.5$ \\
$\mathrm{MWCNT}(\mathrm{NM}-400)$ & $\left(\mathrm{mg} \mathrm{l}^{-1}\right)$ & $>10$ & $>10$ & $<2.0$ & $<2.0$ \\
$\mathrm{CB}$ & $\left(\mathrm{mg} \mathrm{l}^{-1}\right)$ & $>10$ & $>10$ & $<2.0$ & $<2.0$ \\
\hline
\end{tabular}

The lack of response in the $\mathrm{TiO}_{2}$ and carbon material treatments meant that precise values could not be calculated. $144 \mathrm{~h} \mathrm{LC}_{50}$ 's were calculated as these represent the entire duration of the exposures, whilst $96 \mathrm{~h}$ is routinely used in ecotoxicology. Note, however, that the $96 \mathrm{~h}$ period incorporates the embryonic stage and the first $48 \mathrm{~h}$ of the larval stage

Table 3 Nominal and measured concentrations of $\mathrm{TiO}_{2}$ ENMs and bulk

\begin{tabular}{|c|c|c|c|c|c|c|c|}
\hline Treatment & $\begin{array}{l}\text { Nominal concentra- } \\
\text { tion }\left(\mathrm{mg} \mathrm{l}^{-1}\right)\end{array}$ & $\begin{array}{l}\text { Measured concentra- } \\
\text { tion at } 0 \mathrm{~h}\left(\mathrm{mg} \mathrm{l}^{-1}\right)\end{array}$ & $\begin{array}{l}\text { Percentage of } \\
\text { nominal at } 0 \mathrm{~h}\end{array}$ & $\mathrm{CV}(\%)$ & $\begin{array}{l}\text { Measured con- } \\
\text { centration at } 24 \mathrm{~h} \\
\left(\mathrm{mg} \mathrm{l}^{-1}\right)\end{array}$ & $\begin{array}{l}\text { Percentage of } \\
\text { nominal at } 24 \mathrm{~h}\end{array}$ & $\mathrm{CV}(\%)$ \\
\hline Control & 0 & $0.1 \pm 0.0$ & NA & NA & $0.035 \pm 0.026$ & NA & NA \\
\hline $\mathrm{TiO}_{2}$ ENMs & 10 & $1.7 \pm 0.7$ & 16.9 & 41.2 & $0.4 \pm 0.3$ & 4.2 & 75.0 \\
\hline $\mathrm{TiO}_{2}$ ENMs & 20 & $4.8 \pm 1.2$ & 24.1 & 25.0 & $0.9 \pm 0.8$ & 4.4 & 88.9 \\
\hline $\mathrm{TiO}_{2}$ ENMs & 40 & $9.0 \pm 2.8$ & 22.6 & 31.1 & $1.4 \pm 1.0$ & 3.4 & 71.4 \\
\hline $\mathrm{TiO}_{2}$ ENMs & 80 & $18.8 \pm 4.0$ & 23.6 & 21.3 & $1.9 \pm 1.7$ & 2.4 & 89.5 \\
\hline $\mathrm{TiO}_{2}$ ENMs & 160 & $33.7 \pm 7.4$ & 21.0 & 22.0 & $3.2 \pm 2.5$ & 2.0 & 78.1 \\
\hline $\mathrm{TiO}_{2}$ bulk & 10 & $0.9 \pm 0.1$ & 9.0 & 11.1 & $0.2 \pm 0.1$ & 1.7 & 50.0 \\
\hline $\mathrm{TiO}_{2}$ bulk & 20 & $1.2 \pm 1.1$ & 5.9 & 91.7 & $0.7 \pm 0.5$ & 3.3 & 71.4 \\
\hline $\mathrm{TiO}_{2}$ bulk & 40 & $4.2 \pm 1.3$ & 10.5 & 31.0 & $0.5 \pm 0.3$ & 1.2 & 60.0 \\
\hline $\mathrm{TiO}_{2}$ bulk & 80 & $16.0 \pm 6.8$ & 20.0 & 42.5 & $7.5 \pm 0.3$ & 9.3 & 4.0 \\
\hline $\mathrm{TiO}_{2}$ bulk & 160 & $23.1 \pm 4.5$ & 14.4 & 19.5 & $17.5 \pm 0.2$ & 7.8 & 1.1 \\
\hline
\end{tabular}

Data are presented at $0 \mathrm{~h}(10 \mathrm{~min}$ following dosing) and at $24 \mathrm{~h}(10 \mathrm{~min}$ before the daily water change). All samples were taken from the centre of the beaker, and analysis was carried out using ICP-OES, data are mean \pm standard deviation, $n=18$ samples per treatment, NA $=$ not applicable as there was no added $\mathrm{TiO}_{2}, \mathrm{CV}(\%)$ is the coefficient of variation, used to test the within treatment variability $(n=6$ samples per concentration of each material)

\section{$\mathrm{TiO}_{2} \mathrm{ENM}$}

\section{Confirming the exposure}

The highest measured percentage of the nominal dose of $\mathrm{TiO}_{2}$ ENMs in the current experiment was $60.1 \%, 10 \mathrm{~min}$ post-dosing in the $80 \mathrm{mg} \mathrm{l}^{-1}$ treatment (Table 3). However, $24 \mathrm{~h}$ post-dosing, this decreased to just $4.0 \%$. It was clear that both $\mathrm{TiO}_{2}$ ENMs and the bulk material aggregated and settled to the bottom of the exposure beakers, particularly at the higher concentrations. With water samples typically taken from the middle of the water column, these sedimented particles would therefore not have been collected, leading to erroneously low measured ENM concentrations (i.e., unrepresentative sampling of the heterogeneous test water).

\section{Acute toxicity}

Exposure to $\mathrm{TiO}_{2}$ ENMs or $\mathrm{TiO}_{2}$ bulk at concentrations up to $160 \mathrm{mg} \mathrm{l}^{-1}$ did not produce sufficient mortality to calculate $\mathrm{LC}_{50}$ values (Table 2). The lack of acute effects has been seen previously in experiments where zebrafish embryos were exposed to $\mathrm{TiO}_{2}$ EMNs at concentrations reaching $500 \mathrm{mg} \mathrm{l}^{-1}$ (Zhu et al. 2008; Ma and Diamond 2013). The lowest survival in the current study was seen in larvae exposed to $80 \mathrm{mg} \mathrm{l}^{-1} \mathrm{TiO}_{2}$ ENMs where $71.7 \%$ survived by day 6 (Fig. 1a, b). However, survival in the control animals for this experiment was $85.0 \%$ at day 6 (background mortality), and there were no statistically significant differences between any treatments (ANOVA, $P>0.05$ ). Survival was between 78.3 and $93.3 \%$ in all of the other $\mathrm{TiO}_{2}$ treatments (Fig. 1a, b). Where mortality did occur, the zebrafish were not affected during the embryonic stage, with most of the 
(a) $\mathrm{TiO}_{2}$ ENMs

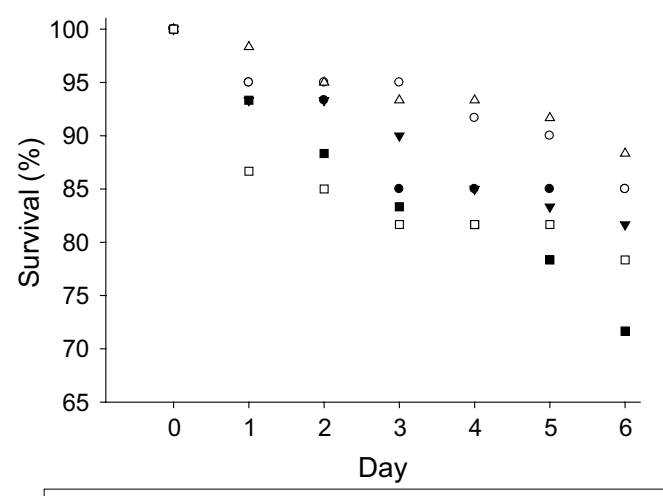

Control $\circ 10 \mathrm{mgl}^{-1}$ - $20 \mathrm{mgl}^{-1} \Delta 40 \mathrm{mgl}^{-1}=80 \mathrm{mgl}^{-1}$ - $160 \mathrm{mgl}^{-1}$

(c) MWCNT

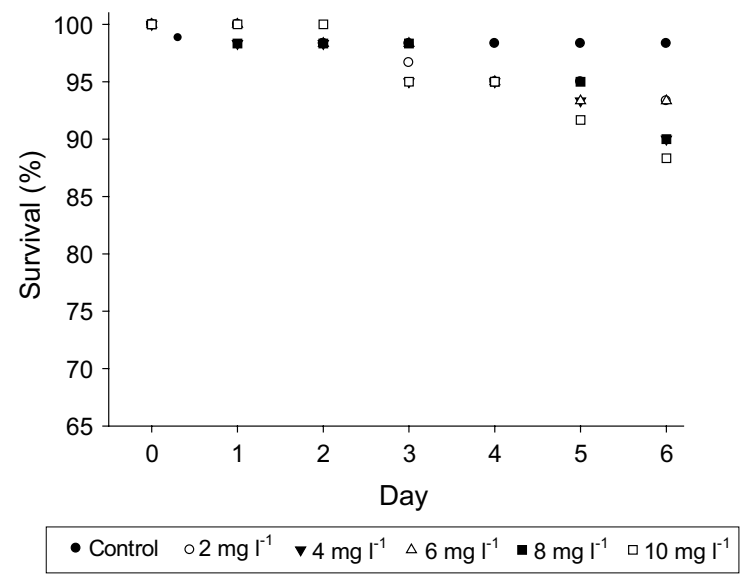

(e) Ag ENMs

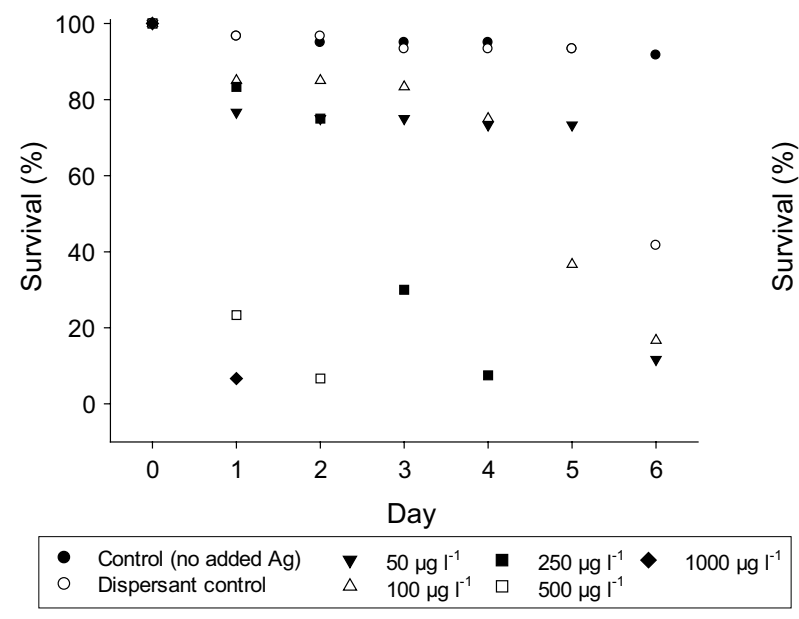

(b) $\mathrm{TiO}_{2}$ bulk

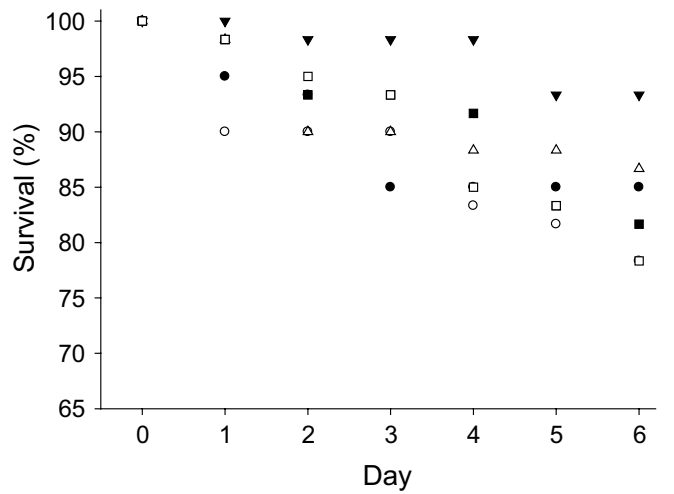

- Control $\circ 10 \mathrm{mg} \mathrm{l}^{-1} \mathbf{\nabla} 20 \mathrm{mg} \mathrm{l}^{-1} \Delta 40 \mathrm{mg} \mathrm{l}^{-1}=80 \mathrm{mg} \mathrm{l}^{-1} \square 160 \mathrm{mg} \mathrm{l}^{-1}$

(d) Carbon black

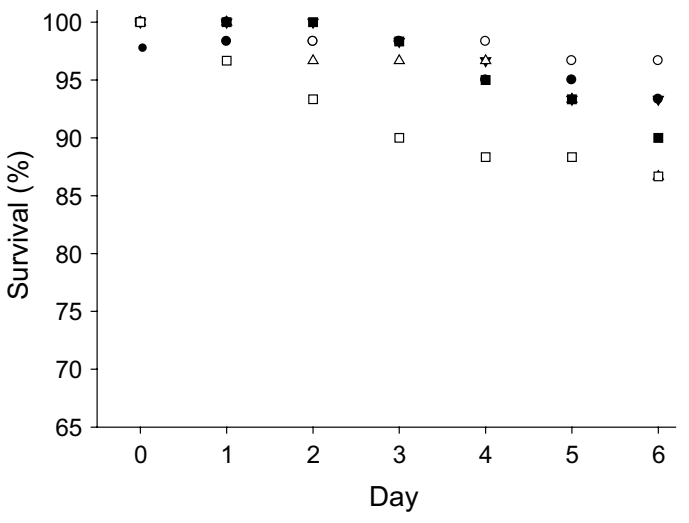

- Control $\circ 2 \mathrm{mg} \mathrm{l}^{-1} \vee 4 \mathrm{mg} \mathrm{l}^{-1} \Delta 6 \mathrm{mg} \mathrm{l}^{-1}$ - $8 \mathrm{mg} \mathrm{l}^{-1} \quad \square 10 \mathrm{mg} \mathrm{l}^{-1}$

(f) $\mathrm{Ag}\left(\right.$ as $\left.\mathrm{AgNO}_{3}\right)$

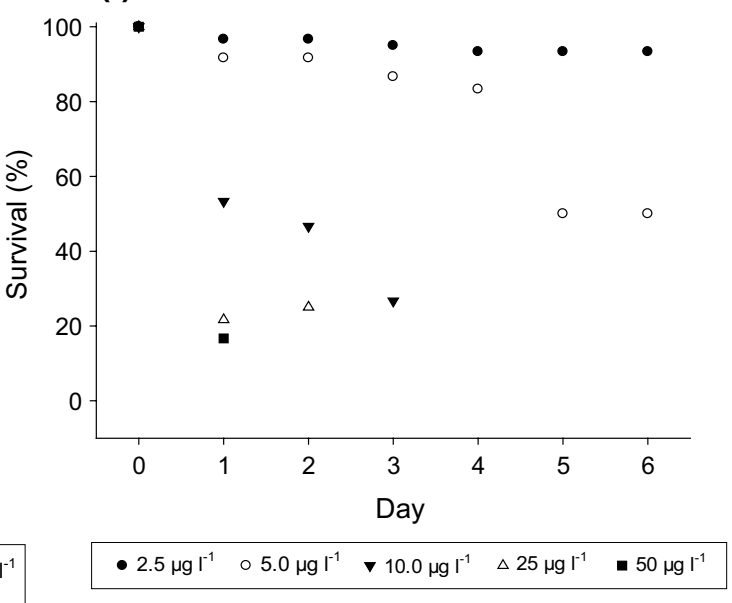

Fig. 1 Survival of zebrafish embryos and larvae exposed in triplicate to a $\mathrm{TiO}_{2}$ ENMs, b bulk $\mathrm{TiO}_{2}$, c MWCNT, $\mathbf{d}$ carbon black, e $\mathrm{Ag}$ ENMs, $\mathbf{f} \mathrm{AgNO}_{3}$ using the original OECD 210 TG. Controls with no added ENM or bulk/metal salt were included throughout, as well as dispersant (NM-300K-Dis) only controls in the Ag experiments. Error bars are omitted for clarity. Where no data are presented, $100 \%$ mortality had occurred at these concentrations by that time point. Data are mean, $n=60$ larvae per treatment 
observed mortality occurring in the hatched larvae following 5 or 6 days of exposure (Fig. 1a, b). In the study by Ma and Diamond (2013), the switch to the use of ultraviolet light in the exposures did cause significant acute toxicity, but here, the hatched larvae (at the eleutheroembryo stage) were more sensitive than the pre-hatch embryos. In the current experiment, a concentration-dependent sedimentation of $\mathrm{TiO}_{2}$ ENMs and bulk was observed in each beaker, which resulted in a settling of material on embryos (smothering) and a pollution avoidance response by hatched larvae (swimming and resting at top of beaker only, compared to swimming and resting throughout the water column in controls).

\section{Swimming behaviour and sublethal toxicity}

Larvae exposed to the highest concentrations of $\mathrm{TiO}_{2}$ ENMs and to a lesser degree $\mathrm{TiO}_{2}$ bulk swam or maintained a resting position towards the top of the beakers, whereas larvae from the control beakers were observed to be swimming or positioned randomly throughout the water column, clearly exhibiting pollution avoidance behaviour.

Exposure to $\mathrm{TiO}_{2}$ ENMs or bulk did not affect hatching success in the current study, although there was a slight concentration-dependent lag in time to hatch which was statistically significant in the $160 \mathrm{mg}^{-1} \mathrm{TiO}_{2}$ ENM treatment. Here, there was approximately $20 \%$ less hatching at $48 \mathrm{~h}$ than in all of the other treatments (ANOVA, $P<0.05$ ). Larvae length was not affected by exposure to $\mathrm{TiO}_{2}$ ENMs. Similarly, no significant differences were seen in muscle block width or yolk sac volume following exposure to $\mathrm{TiO}_{2}$ ENMs or bulk.

\section{MWCNT}

\section{Confirming the exposure}

At present, it is not possible to quantitatively confirm the exposure of MWCNT due to a lack of analytical techniques that can distinguish between the MWCNT and other forms of carbon in the sample. Attempts were therefore made to assess the concentration of cobalt (Co) in the experimental water. Cobalt is used as a catalyst in the production of the MWCNT and is therefore present as a metal impurity. However, there were no measurable levels of $\mathrm{Co}$ in the water samples (data not shown). A slight, though noticeable, density gradient was visible in the beakers containing $10 \mathrm{mg} \mathrm{l}^{-1}$ MWCNT (the highest concentration), indicting aggregation of this material. This has obvious implications for exposure and the subsequent interpretation of the dose-response.

\section{Acute toxicity}

Overall, MWCNT and carbon black showed low acute toxicity to ELS zebrafish at the concentrations tested here (up to $10 \mathrm{mg} \mathrm{l}^{-1}$ ). Mortality was less than $15 \%$ at the highest concentration of each material (Fig. 1c, d), and as such, it was not possible to calculate an $\mathrm{LC}_{50}$. None of the mortality occurred during the embryonic stage, which is in agreement with the literature where concentrations of MWCNT up to $100 \mathrm{mg} \mathrm{l}^{-1}$ did not cause mortality in zebrafish embryos (e.g., Rojo et al. 2007; Liu et al. 2014). Similar effects have been seen in studies with single-walled carbon nanotube (SWCNT), with concentrations as high as $360 \mathrm{mg}^{-1}$ failing to affect the survival of zebrafish embryos (Cheng et al. 2007). A study exposing early-life stage rare minnows (Gobiocypris rarus) to $0-360 \mathrm{mg} \mathrm{l}^{-1}$ SWCNT found that survival was only reduced after the larvae had hatched (Zhu et al. 2015). Much of the limited mortality seen in the current study also occurred posthatch, further highlighting the low toxicity of this material to fish embryos. This is most likely due to the protective barrier provided by the chorion. The sensitivity of pre-hatch embryos to MWCNT has been seen in a microinjection study. In their work, Cheng and Cheng (2012) introduced fluorescent-labelled MWCNT (2 ng equivalent weight) directly into the embryonic cells of one-cell-stage zebrafish. They observed $100 \%$ mortality in exposed embryos within 8-10 hpf, again demonstrating the effectiveness of the chorion in protecting the animal.

\section{Swimming behaviour and sublethal toxicity}

Hatched larvae avoided the bottom of the beaker and thus the aggregated MWCNT, but showed no other signs of altered swimming behaviour or distress. As with $\mathrm{TiO}_{2}$ ENMs, there were no effects to growth (total length or muscle block width) or yolk sac volume (data not shown).

\section{Ag ENM}

\section{Confirming the exposure}

As the nominal concentration of Ag ENMs increased, the amount measured by ICP-MS or OES decreased (concentration-dependent effect) (Table 4). However, even at the lower Ag ENM concentrations, it was not possible to measure concentrations equal or greater than $80 \%$ and was as low as $16.9 \%$ of the nominal concentration 10 min post-dosing in the $1000 \mu \mathrm{g} \mathrm{l}^{-1} \mathrm{Ag}$ ENM treatment. The Ag ENMs used here were supplied with a capping agent in order to improve dispersion, and yet, even this approach failed to meet the criteria for maintaining the test substance concentrations.

\section{Acute toxicity}

Survival was not affected in the dispersant control treatment in the $\mathrm{Ag}$ experiments indicating that any effects 
Table 4 Nominal and measured concentrations of $\mathrm{Ag}$ ENMs and $\mathrm{AgNO}_{3}$

\begin{tabular}{|c|c|c|c|c|c|c|c|}
\hline Treatment & 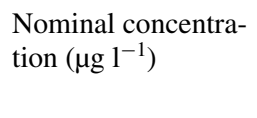 & $\begin{array}{l}\text { Measured con- } \\
\text { centration at } 0 \mathrm{~h} \\
\left(\mathrm{mg} \mathrm{l}^{-1}\right)\end{array}$ & $\begin{array}{l}\text { Percentage of } \\
\text { nominal at } 0 \mathrm{~h}\end{array}$ & CV (\%) & $\begin{array}{l}\text { Measured con- } \\
\text { centration at } 24 \mathrm{~h} \\
\left(\mathrm{mg} \mathrm{l}^{-1}\right)\end{array}$ & $\begin{array}{l}\text { Percentage of } \\
\text { nominal at } 24 \mathrm{~h}\end{array}$ & $\mathrm{CV}(\%)$ \\
\hline Control & 0 & $0.02 \pm 0.0$ & NA & NA & $0.005 \pm 0.0$ & NA & NA \\
\hline Dispersant cont. & 0 & $0.06 \pm 0.0$ & NA & NA & $0.080 \pm 0.0$ & NA & NA \\
\hline Ag ENMs & 50 & $37.5 \pm 9.6$ & 74.9 & 25.6 & $33.2 \pm 8.9$ & 66.5 & 26.8 \\
\hline Ag ENMs & 100 & $78.1 \pm 22.8$ & 78.1 & 29.2 & $71.0 \pm 26.3$ & 71.0 & 37.0 \\
\hline Ag ENMs & 250 & $173.1 \pm 24.1$ & 69.2 & 13.9 & $162.1 \pm 23.8$ & 64.8 & 14.7 \\
\hline Ag ENMs & 500 & $177.9 \pm 42.1$ & 32.1 & 23.7 & $168.5 \pm 27.3$ & 33.7 & 16.2 \\
\hline Ag ENMs & 1000 & $169.2 \pm 53.3$ & 16.9 & 31.5 & $167.1 \pm 48.6$ & 16.7 & 29.1 \\
\hline $\mathrm{AgNO}_{3}$ & 2.5 & $2.2 \pm 0.1$ & 89.1 & 4.5 & $2.0 \pm 0.2$ & 82.4 & 10.0 \\
\hline $\mathrm{AgNO}_{3}$ & 5 & $4.6 \pm 0.9$ & 92.3 & 19.6 & $4.4 \pm 0.7$ & 87.2 & 15.9 \\
\hline $\mathrm{AgNO}_{3}$ & 10 & $9.1 \pm 0.6$ & 90.8 & 6.6 & $8.4 \pm 1.0$ & 83.7 & 11.9 \\
\hline $\mathrm{AgNO}_{3}$ & 25 & $23.6 \pm 1.1$ & 94.5 & 4.7 & $22.1 \pm 1.4$ & 88.3 & 6.3 \\
\hline $\mathrm{AgNO}_{3}$ & 50 & $46.5 \pm 2.4$ & 93.0 & 5.2 & $41.3 \pm 3.7$ & 82.7 & 9.0 \\
\hline
\end{tabular}

Data are presented at $0 \mathrm{~h}$ (10 min following dosing) and at $24 \mathrm{~h}$ (10 min before the daily water change). All samples were taken from the centre of the beaker, and analysis was carried out using ICP-OES for Ag ENMs and ICP-MS for $\mathrm{AgNO}_{3}$, data are mean \pm standard deviation, $n=18$ samples per treatment, $\mathrm{NA}=$ not applicable as there was no added Ag, CV $(\%)$ is the coefficient of variation, used to test the within treatment variability $(n=6$ samples per concentration of each material)

seen in the Ag ENM treatments were as a result of the particles only and not caused by the dispersing agent. Both $\mathrm{Ag}$ ENMs and $\mathrm{AgNO}_{3}$ were acutely toxic to zebrafish (Figs. 1, 2), though the latter was more toxic with a 6-day $(144 \mathrm{~h}) \mathrm{LC}_{50}$ value approximately ten-fold lower than for the Ag ENMs (Table 2). A NOEC was calculated for Ag ENMS, but again, the concentrations were not low enough for a NOEC to be calculated for the $\mathrm{AgNO}_{3}$ (Table 2). Interestingly, the NOEC for the Ag ENMs decreased significantly between $96 \mathrm{~h}\left(23.1 \mu \mathrm{g} \mathrm{l}^{-1}\right)$ and $144 \mathrm{~h}\left(3.9 \mu \mathrm{g}^{-1}\right)$. The 96-h animals had been exposed for half of that time period as embryos which indicates the increased sensitivity of eleutheroembryos (i.e., hatched, but still using their yolk sac for nutrition) and larvae to $\mathrm{Ag}$ ENMs compared to embryos.

Significantly reduced survival was observed in embryos exposed to both Ag ENMs and $\mathrm{AgNO}_{3}$. Survival was 6.67 and $16.67 \%$ in the $1000 \mu \mathrm{g} \mathrm{l^{-1 }} \mathrm{Ag}$ ENM and $50 \mu \mathrm{g}^{-1}$ $\mathrm{AgNO}_{3}$ treatments at $24 \mathrm{hpf}$, respectively, and $0 \%$ in both treatments by $48 \mathrm{~h}$ (still prior to hatching, Fig. 1e, f). However, although both Ag materials were able to impart toxic effects to the embryos, the mechanisms of toxicity are likely to be different, particularly as the exposures did not commence until the chorion had hardened (i.e., $>1 \mathrm{hpf}$ ). The chorion enveloping the embryo and the perivitelline fluid within, both present barriers that offer some protection from exposure to contaminants. Negatively charged sulfhydryl groups within the chorion can tightly bind cations such as $\mathrm{Ag}, \mathrm{Cu}$ and $\mathrm{Hg}$ (Rombough 1985), with $85 \%$ of whole embryo Ag burden bound to the chorion in rainbow trout embryos exposed to waterborne $\mathrm{Ag}$ (as $\mathrm{AgNO}_{3}$,
Guadagnolo et al. 2001). It is likely, however, that either the binding sites were effectively overwhelmed by the higher $\mathrm{Ag}$ (as $\mathrm{AgNO}_{3}$ ) concentrations used here or that the chorionic structure was compromised, thereby facilitating $\mathrm{Ag}$ (from $\mathrm{AgNO}_{3}$ ) access to the embryo. The permeability of the chorion to Ag ENMs has been demonstrated previously. Asharani et al. (2008) used transmission electron microscopy to assess the distribution of Ag ENMs in zebrafish embryos and found the particles in the brain, heart, yolk and blood of exposed animals. A study assessing the transport of single Ag ENMs into zebrafish embryos found that the particles transported in and out of the embryo via the chorion pore canal using Brownian diffusion (Lee et al. 2007). The diameter of chorion pores is approximately 0.5-0.7 $\mu \mathrm{m}$ (Rawson et al. 2000) and are therefore large enough to allow even aggregated ENMs through (MacCormack et al. 2014). Although no attempts were made during the current experiments to image the ENMs within the embryos, it is feasible that they were also able to enter via the chorionic pore, causing the toxic effects seen. The primary particles size of the NM-300K ENMs used here was $<20 \mathrm{~nm}$, and although larger aggregates were formed in solution (around 50-75 nm, Table 1), their relatively small size could still allow a significant portion of them to enter the chorion via the canal.

\section{Swimming behaviour and sublethal toxicity}

There were no obvious density gradients visible in the beakers from the Ag ENM exposure, and hatched larvae were distributed throughout the water column with no 
(a) Ag ENMs

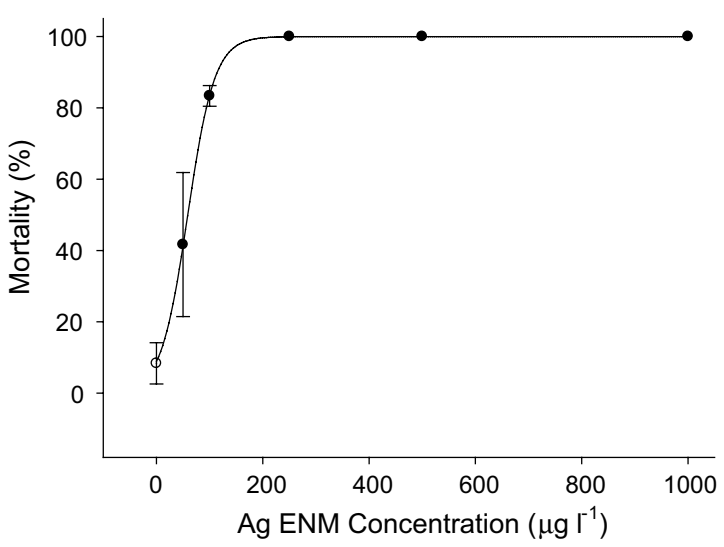

(b) $\mathrm{Ag}\left(\mathrm{as}_{\mathrm{AgNO}}\right.$ )

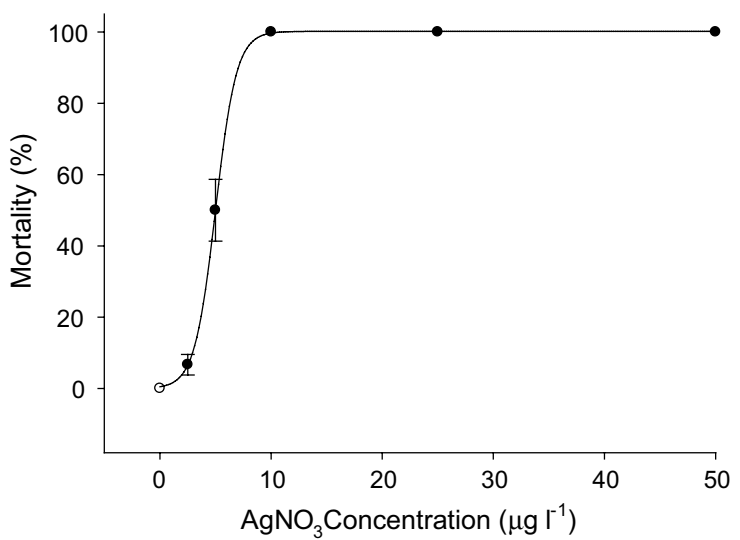

Fig. 2 Mortality of ELS zebrafish at the end of the experiment (day 6) from exposure to a Ag ENMs and $\mathbf{b} \mathrm{AgNO}_{3}$. Data are mean $\pm \mathrm{SEM}$, $n=60$ larvae per treatment. Note, the different nominal exposure concentrations used ( $x$-axis)

Table 5 Morphometric analysis of zebrafish larvae exposed to Ag ENMs or $\mathrm{AgNO}_{3}$ for 6 days using the standard OECD 210 TG

\begin{tabular}{llll}
\hline Treatment & Length $(\mathrm{mm})$ & Yolk sac volume $\left(\mathrm{mm}^{3}\right)$ & Muscle block width $(\mathrm{mm})$ \\
\hline Control & $3.72 \pm 0.24(0.07)^{\mathrm{ab}}$ & $17.17 \pm 5.74(1.66)^{\mathrm{a}}$ & $226.86 \pm 25.44(7.67)^{\mathrm{a}}$ \\
Dispersant control & $3.76 \pm 0.22(0.06)^{\mathrm{a}}$ & $14.57 \pm 4.80(1.39)^{\mathrm{a}}$ & $249.63 \pm 35.37(10.66)^{\mathrm{ab}}$ \\
$2.5 \mu \mathrm{g} \mathrm{l}^{-1} \mathrm{AgNO}_{3}$ & $3.73 \pm 0.16(0.05)^{\mathrm{ab}}$ & $24.98 \pm 5.85(1.69)^{\mathrm{a}}$ & $270.01 \pm 22.64(6.54)^{\mathrm{b}}$ \\
$5 \mu \mathrm{g} \mathrm{l}^{-1} \mathrm{AgNO}_{3}$ & $3.57 \pm 0.26(0.07)^{\mathrm{b}}$ & $37.72 \pm 19.49(5.63)^{\mathrm{b}}$ & $267.78 \pm 33.27(9.60)^{\mathrm{b}}$ \\
$50 \mu \mathrm{g} \mathrm{l}^{-1} \mathrm{Ag} \mathrm{ENMs}^{\mathrm{a}}$ & $3.36 \pm 0.19(0.06)^{\mathrm{c}}$ & $19.04 \pm 6.81(1.97)^{\mathrm{a}}$ & $248.44 \pm 27.44(8.27)^{\mathrm{a}}$ \\
$100 \mu \mathrm{g} \mathrm{l^{-1 }} \mathrm{Ag} \mathrm{ENMs}^{\mathrm{a}}$ & $3.25 \pm 0.240 .08)^{\mathrm{c}}$ & $35.53 \pm 13.16(4.16)^{\mathrm{b}}$ & $268.46 \pm 19.63(6.21)^{\mathrm{b}}$ \\
\hline
\end{tabular}

Data are mean \pm SD (S.E.M.), $n=12$ samples per treatment. Different letters indicate statistically significant differences (ANOVA or Kruskal-Wallis, $P<0.05$ ). Note, because of the high mortality seen in this experiment only the treatments listed in the table above had remaining larvae at the end of day 6 to facilitate the morphometric analysis opportunity for avoidance behaviours. However, larvae were noticeably lethargic with increased Ag ENM and $\mathrm{AgNO}_{3}$ concentrations, with some only moving following physical stimulus.

An assessment of hatching success and time to hatch in the Ag ENM exposures was difficult due to the high mortality seen in that experiment. However, there appeared to be a minor concentration-dependent, though non-significant, effect on both of these endpoints (ANOVA, $P>0.05$, data not shown), though a dedicated sublethal exposure would be necessary to elucidate this further.

The morphometric analysis carried out in the current study did show some effects following exposure to $\mathrm{Ag}$ ENMs, though again the mortality seen in larvae exposed to the highest concentrations of both $\mathrm{Ag}$ ENMs and $\mathrm{AgNO}_{3}$ meant that it was not possible to assess morphometrics in all fish at all concentrations. Surviving larvae at the end of the exposures showed a statistically significant concentration-dependent reduction in total length following exposure to Ag ENMs (ANOVA, $P<0.05$, Table 5) and was shown to be a relevant endpoint for the toxicological testing of this material. The control larvae had a mean total length of $3.72 \mathrm{~mm}$ compared to mean lengths of 3.36 and $3.25 \mathrm{~mm}$ in the 50 and $100 \mu \mathrm{g} \mathrm{l}^{-1} \mathrm{Ag}$ ENM treatments, respectively, representing 9.7 and $12.6 \%$ reductions in total length compared to control larvae (significantly different to controls, ANOVA, $P<0.05$ ). A similar effect was also seen in larvae exposed to $5.0 \mu \mathrm{g} \mathrm{l}^{-1} \mathrm{AgNO}_{3}$ (Table 5), showing the utility of this measurement for both ENMs and dissolved chemicals outside of regulatory testing.

Interestingly, although a reduction in total length was seen in larvae exposed to 100 and $5 \mu \mathrm{g} \mathrm{l^{-1 }} \mathrm{Ag}$ ENMs and $\mathrm{AgNO}_{3}$ respectively, both of these treatments also saw a simultaneous increase in muscle block width compared to controls (ANOVA, $P<0.05$, Table 5). Although myogenesis can be affected by environmental stress (Müller 2008), when considering the relatively short time frame of the current experiments, a more likely explanation is osmotic stress resulting in muscle turgidity. A relative increase in extracellular space and a concomitant decrease in muscle fibre size has previously been observed with copper ENMs in trout (Al-Bairuty et al. 2013). Also, in the present 
(a)

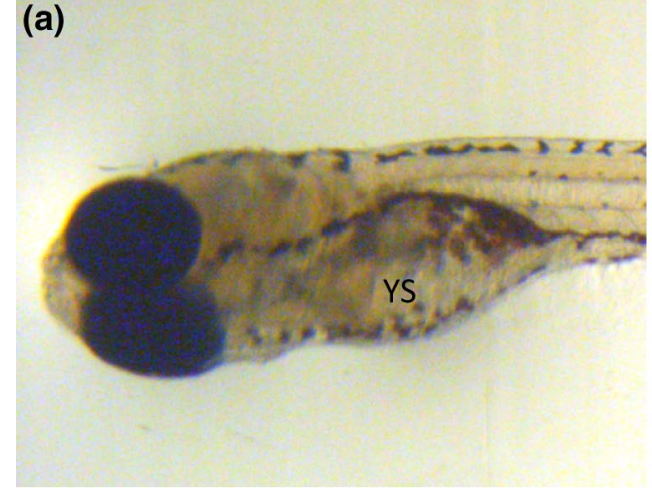

(b)

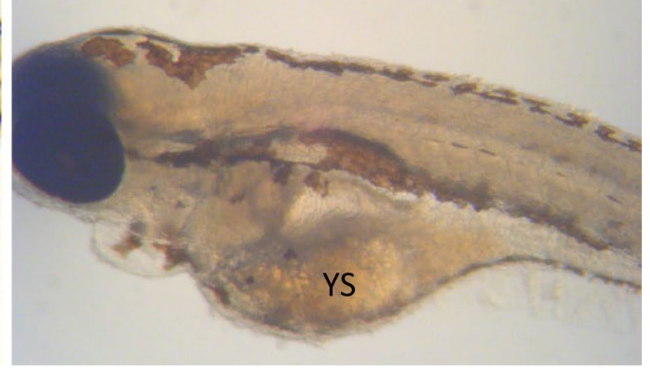

Fig. 3 Micrographs showing yolk sacs (YS) of a control larvae and b larvae exposed to $100 \mu \mathrm{g} \mathrm{l}^{-1} \mathrm{Ag}$ ENMs for 6 days (144 h) with the latter exhibiting oedema in the yolk sac (Meiji binocular microscope, $\times 70$ magnification)

study, a significant increase in yolk sac volume was seen larvae from the $5 \mu \mathrm{g} 1^{-1} \mathrm{AgNO}_{3}$ and $100 \mu \mathrm{g}^{-1} \mathrm{Ag}$ ENM treatments compared to all other treatments and controls (ANOVA, $P<0.05$, Table 5; Fig. 3), suggesting either oedema in the yolk sac or lack of utilisation of the contents.

\section{Was the OECD 210 test effective for assessing ENM toxicity to fish?}

Several issues arose when conducting toxicity tests with the OECD 210 TG. Some of these were nano-specific, and whilst the recent update (OECD 2013) to the original TG released in 1992 addressed some of the fundamental flaws with respect to fish biology and producing robust data, some generic problems still remain. Both the nano and more general issues are discussed below and are summarised in Table 6 along with suggestions to improve the test.

\section{Rationale behind the test}

The TG states that: Tests with the early-life stages of fish are intended to define the lethal and sublethal effects of chemicals on the stages and species tested. However, there are some problems with this strategy. Firstly, one must question the validity of using a combination of lethal and sublethal endpoints, over what is essentially a chronic duration. For example, if the embryos experience high mortality, then the test will not inform upon effects to free swimming larvae. Chronic tests were designed to assess adverse effects from sublethal concentrations over time (to provide information not available from shorter, acute tests) (Rand et al. 1995). These data are needed in ENM toxicity, where predicted environmental concentrations are low. Also, it has been seen previously that exposure to chemicals at an early life stage may have consequences for later stages, that perhaps would not occur if the later life stage only was exposed. For example, dissolved $\mathrm{Cu}$ exposure to the embryos of a cyprinid fish (Leuciscus idus) resulted in reduced toxicity in the hatched larvae compared to larvae exposed post-hatching only (Witeska et al. 2014). A similar effect was seen with $\mathrm{Cd}$, where free-feeding larvae were more sensitive when not exposed as embryos and yolk sac larvae, than those that were exposed throughout these life stages (Brinkman and Hansen 2007). This has environmental implications and requires further investigation for ENMs (see "Is a test spanning both the embryonic and larval stages of fish development suitable for use with ENMs?" section).

\section{Dosing the test vessels}

With regards to dosing the experimental vessels the TG state: The test system should preferably be conditioned with concentrations of the test chemical for a sufficient duration to demonstrate stable exposure concentrations prior to the introduction of test organisms. During a 2014 workshop attended by several international experts, one of the approaches discussed was to allow ENMs to reach a pseudosteady state prior to the addition of the test fish (Petersen et al. 2015), akin to the OECD 210 TG. The pseudosteady state is the point where the ENMs appear to have reached equilibrium in terms of agglomeration, settling and dissolution kinetics, with acceptably low or no further measureable changes (Petersen et al. 2015). However, with this approach, one could essentially be missing the initial and perhaps greatest, 'window of exposure' (in terms of concentration). Furthermore, this is likely influenced by several factors including water chemistry, analytical techniques and instrumentation, the individual opinion of the researcher, and even test vessel volume. As such, the methodology would require standardisation. Also, in terms of environmental relevance, it is highly unlikely that early-life stage fish will move into a polluted environment, and therefore, it seems pertinent to add the fish prior to the ENMs. 


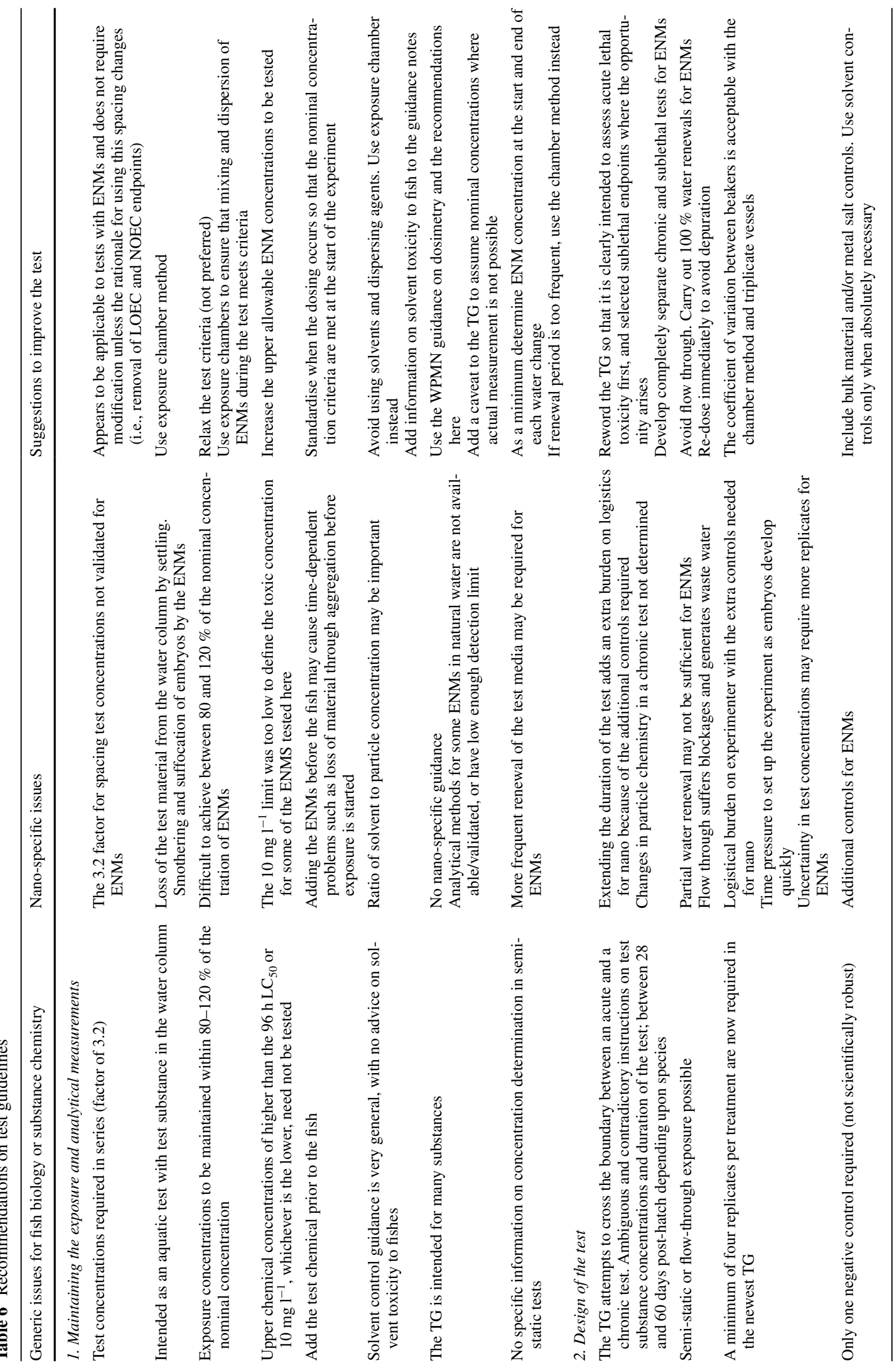




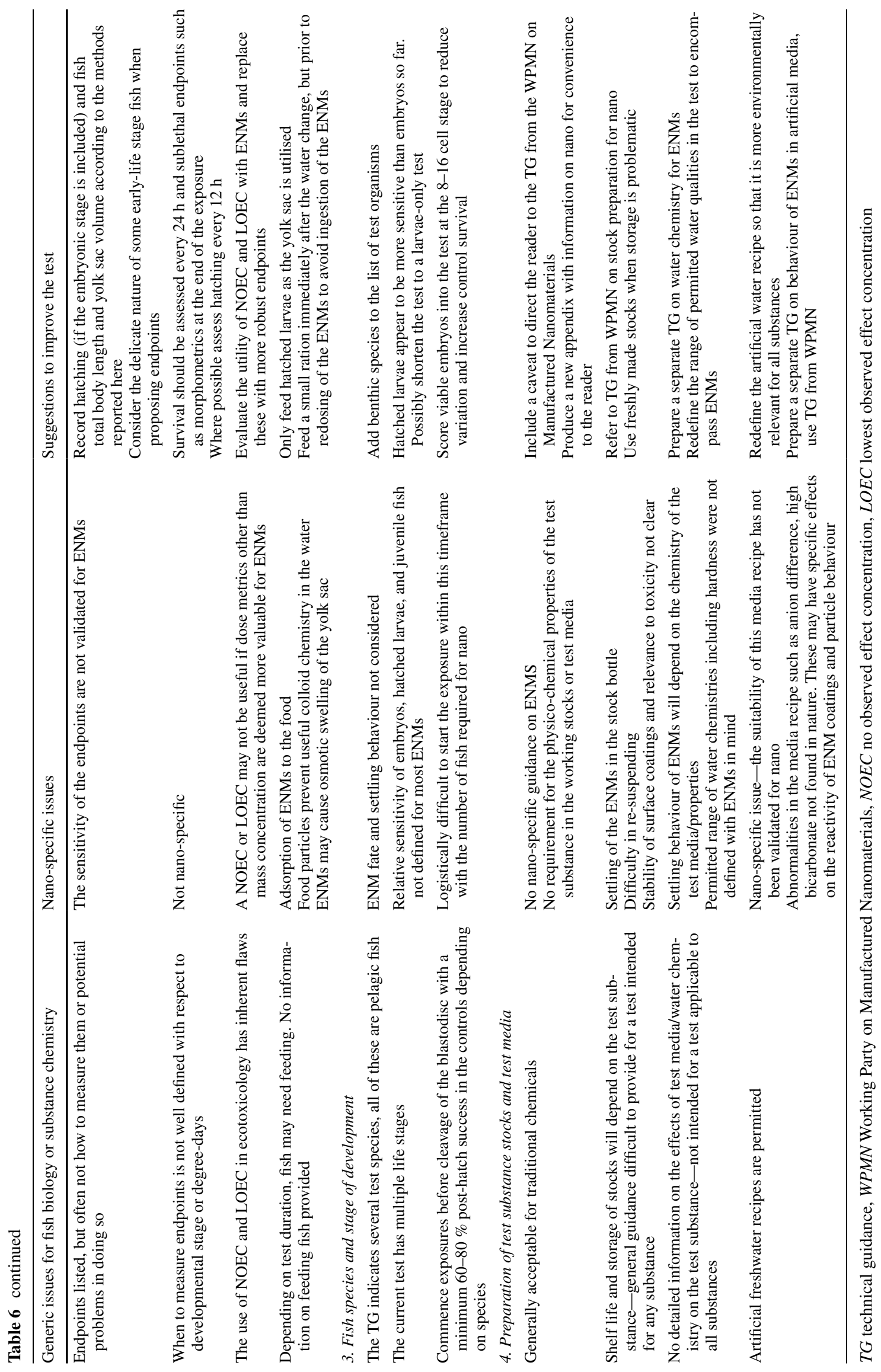


Indirectly related to dosing is the issue of feeding the fish. Although for short, acute tests, the withdrawal of food is routine and does not harm adult or even juvenile fish (Handy et al. 2012b); this approach is not appropriate for early-life stage fish. The yolk sac stage is relatively shortlived, and when depleted, the larvae are no longer nutritionally self-sufficient and have no fat reserves. At this point, it is critical to feed the fish in order to ensure their survival. However, this presents a special problem for the early-life stage test where feeding may confound particle characterisation in the water or the route of exposure (i.e., unintentional dietary exposure as the ENMs stick to the feed). Furthermore, uneaten feed pellets are often removed from the tanks, but this would result in the simultaneous removal of ENMs from the exposure. These problems create additional uncertainty in experiments with ENMs and require consideration in future TG.

\section{Maintaining the exposure}

A principal concern with the aqueous testing of ENMs is the ability to maintain exposure concentrations in the water column in order to meet standard test criteria. This is traditionally $\geq 80 \%$ of nominal concentrations for a fish test (e.g., OECD 1992b), and a failure to meet this validation criterion may result in a rejection of the data (Handy et al. 2012b). The original OECD 210 TG (OECD 1992a) stipulated that concentrations of the test substance in solution had to be satisfactorily maintained within $\pm 20 \%$ of the mean measured values. However, this has been amended in the updated TG (OECD 2013), and the only indication of desirable measured exposure concentrations now comes from the following statement: When the measured concentrations do not remain within 80-120\% of the nominal concentration, the effect concentrations should be determined... The aggregation and subsequent loss of ENMs from a colloidal dispersion in solution has been frequently observed, often resulting in ENM concentration levels in the water column that would be below the acceptable limits in regulatory testing (e.g., Ag ENMs, Lee et al. 2012; Cu ENMs, Griffitt et al. 2007; $\mathrm{TiO}_{2}$ ENMs, Clemente et al. 2014). Furthermore, the relatively unpredictable behaviour of ENMs in solution and subsequent lack of reproducibility in achieving similar exposure concentrations in test vessels would also be likely to invalidate the test criteria. Flow though tests are preferred in the OECD $210 \mathrm{TG}$ and are often used due to their ability to maintain dispersions and concentrations of the test chemical in the water column as well as providing sensitive fish species with well-oxygenated water and low ammonia levels (Handy et al. 2012b). However, even for traditional (i.e., dissolved) chemicals, these tests involve the use of somewhat complicated delivery systems and require large volumes of test water and thus test chemical (Welsh et al. 2008). This in turn produces large volumes of hazardous waste water and overall can prove costly compared to static or semi-static systems, increased further if expensive ENMs are tested (Handy et al. 2012a, b). Furthermore, there are concerns that ENMs may stick to or clog the exposure apparatus and that settled ENMs may not be removed from the exposure vessels, thereby increasing ENM concentrations (Petersen et al. 2015). Another consideration is the maintenance of the ENM stock required to deliver the materials to the test vessels (i.e., within a metering pump or diluter). For example, this may require continuous sonication with currently unknown consequences as well as other issues such as the dissolution of metallic ENMs over time. The combination of these factors means that flows through tests are generally impractical for ENMs.

In the absence of a flow-through system, the renewal of the test substance can be achieved through water changes with subsequent redosing (semi-static design). Two approaches to this are recommended in OECD 210. Firstly, the animals can be transferred into separate, but identical test vessels containing the test substance or secondly a proportion (e.g., 2/3) of the test water can be removed and an appropriate volume of freshwater added and the vessel then redosed accordingly. However, because ENMs readily fall out of suspension, it is very difficult to accurately remove a homogeneous proportion with the latter approach. Therefore, in the current study, it was necessary to adopt the approach of using duplicate test vessels to carry out water changes. This was carried out every $24 \mathrm{~h}$, though this itself caused further problems in terms of handling stress on the fish. The TG state that when transferring larvae they should not be exposed to air. Therefore, plastic Pasteur pipettes were used to transfer embryos and larvae to new test beakers, with care taken to minimise the amount of water transferred with the animals in order to negate any changes to nominal substance concentrations in the new beakers. However, some problems with this approach became apparent. Firstly, some of the embryos were accidently dechorionated when using the pipettes, and secondly, it was difficult to capture swimming larvae (increasingly so with age), and the actions in doing so likely caused stress to the animals. This is exacerbated when using ENMs that cloud the water (e.g., $\mathrm{TiO}_{2}$ ENMs), making it more difficult to see the fish. Some larvae in the high $\mathrm{TiO}_{2}$ ENM treatments also became buried in the aggregates of ENMs found at the bottom of the beakers, particularly as they attempted to avoid capture. Furthermore, if the test was to run up to its full duration (up to 30 days post-hatch for zebrafish), then the logistics of daily water changes could prove difficult and may not be financially viable or practical for a commercial laboratory (Handy et al. 2012b). 
Is the test substance concentration criteria in OECD 210 fit for purpose with ENMs?

Many of the original OECD TG, including OECD 210, were designed to assess dissolved chemicals (OECD 2013; Petersen et al. 2015) and as ENMs do not readily dissolve in solution, this can lead to problems with the test. The recently updated OECD 210 TG (OECD 2013) states that if the measured concentrations do not remain within $80-120 \%$ of the nominal value, then the effects concentration should be determined... and expressed relative to the geometric mean of the measured concentrations for semi-static tests (further guidance provided in a separate documents, OECD 2000). Exposure concentrations were not maintained between these values in the current experiments, but this amendment to the TG means that the test validity criteria were not failed per se. This is a welcome addition to the TG, though it should remain desirable to attempt to maintain concentrations within this 80-120\% limit of variation from the nominal values. Doing so does represent a scientifically valid approach, with the established paradigm being that response is proportionally related to dose. However, for some ENMs, this is difficult or even impractical to achieve, and the value of such limits for ENM testing should be considered (Petersen et al. 2014). Furthermore, it may be desirable to assess toxicity by alternative dose metrics to mass concentration, such as particle number concentration, size distribution or surface area (Handy et al. 2012a; Petersen et al. 2015). The reasons why ENMs are lost from the water column also need to be considered. For traditional chemicals, these losses may be attributed to actual removal from the test systems (e.g., by volatilisation and chemical degradation processes) (Petersen et al. 2015), whilst ENMs may still be present, but have settled out or stuck to vessel walls, etc. Moreover, technical limitations in quantifying ENMs do not necessarily mean they are absent from the test media.

When assessing test substance concentrations using the old OECD 210 TG (OECD 1992a), it was apparent how variable the results were with ENMs. In this TG, the measured test chemical concentrations had to be satisfactorily maintained within $\pm 20 \%$ of the mean measured values. For example, in the current experiments, the individual measured values from the $10 \mathrm{mg} \mathrm{l}^{-1} \mathrm{TiO}_{2}$ ENM treatment deviated between 60.8 and $219.2 \%$ from the mean immediately following dosing and from 16.9 to $240.8 \%$ after $24 \mathrm{~h}$. Although not now required as part of OECD 210, these data do highlight the difficulty in achieving uniform and reproducible dispersions with ENMs.

Currently, the TG has an upper concentration limit that should not exceed the $96 \mathrm{~h} \mathrm{LC}_{50}$ value or $10 \mathrm{mg}^{-1}$ (whichever is lower). However, as seen in the current experiments, this was not high enough to elicit a toxicological response in the $\mathrm{TiO}_{2}$ ENM experiments. Raising the upper allowable test concentration is a point of debate. In order to gain specific dose-response data, the concentration needs to be high enough to produce a measurable response in the animal, but from a regulators point of view, these concentrations may be environmentally unrealistic and thus not useful to assess.

\section{Analytical measurements}

In the Frequency of Analytical Determinations and Measurements section of the TG, it states: Analytical methods required should be established, including an appropriate limit of quantification (LOQ) and sufficient knowledge on the substance stability in the test system. However, for ENMs, we cannot reasonably claim to fully meet these prerequisites. As discussed elsewhere (e.g., von der Kammer et al. 2012), the development of appropriate analytical techniques and instrumentation is the focus of international research, but is not yet routinely available. Also, although progress has been made in understanding the behaviour of ENMs in solution, there are still no universally accepted paradigms. The dynamics of ENMs in test media changes with particle characteristics (including any changes to surface chemistry), abiotic factors and time, and research is still needed to fully elucidate these behaviours.

In order to characterise (confirm) the exposure, the TG recommend at least five determinations throughout the duration of the exposure. For flow-through tests, this should be carried out in at least one replicate per concentration each week, whilst there are no further instructions for semi-static tests. Given the changes over time and variability between replicates for the ENMs tested here, there is a need to increase the measurements from those recommended in the TG. There is also a requirement in the TG to filter $(0.45 \mu \mathrm{m}$ pore size $)$ or centrifuge water samples prior to measuring. However, this is not practical for ENMs where aggregates may get caught in the filter, even if below the $0.45-\mu \mathrm{m}$ cut-off size and the filter is saturated before use.

Are the sublethal endpoints appropriate for use with ENMs?

Although nano-specific endpoints or biomarkers are desirable and might simplify ENM toxicity testing, it is unlikely that appropriate endpoints will be discovered or developed in the short term (Handy et al. 2012b). A more plausible task is to identify a suite of toxicological responses following exposure to the major types of ENMs and use these to indicate possible exposure (Handy et al. 2012b). For assessing sublethal effects, the OECD 210 TG suggests recording abnormal behaviour and abnormal (morphological) appearance at adequate intervals. However, there are no specific 
instructions or recommendations on how to assess any abnormalities or to quantify them (i.e., through a classification or scoring system). Furthermore, due to the small size of zebrafish larvae (approximately $3-4 \mathrm{~mm}$ ), it is very difficult to accurately assess behavioural abnormalities such as hyperventilation and uncoordinated swimming (as are suggested in OECD 210). Some commentary on sublethal observations in our experiments with ENMs is given below in relation to the test method.

\section{Swimming behaviour and quiescence}

Although swimming and quiescence were not assessed quantitatively during the current work (e.g., by video tracking analysis), it was clear that hatched larvae exhibited a pollution avoidance response to both the $\mathrm{TiO}_{2}$ ENMs and the $\mathrm{TiO}_{2}$ bulk. This was most evident at the higher $\mathrm{TiO}_{2}$ ENM exposure concentrations where aggregated particles sedimented on the bottom of the beaker forming a layer of $\mathrm{TiO}_{2}$. This observation implies that the settling of the test substance creates the opportunity for the animals to avoid exposure, thus undermining one of the fundamental assumptions in experimental toxicology that the toxic response is associated with the compound administered. However, the avoidance behaviour itself may be a useful endpoint for substances that settle out of the water column.

\section{Hatching}

The numerous studies showing that ENMs affect hatching (review; Celá et al. 2014) suggest that this is a suitable endpoint for assessing the toxicity of ENMs to fish embryos. The approach in OECD 210 of combining both lethal and sublethal endpoints can evidently prove somewhat problematic (e.g., disparate sample numbers due to mortality), though this is a generic rather than a nanospecific issue. Moreover, an issue with the current OECD 210 TG is the lack of more specific and robust instructions on how to accurately assess the effects to hatching. Although the guidance notes do state that hatching should be assessed at least once a day, conducting daily observations only is clearly inadequate and can lead to inaccuracies in the data. For example, if an embryo hatches shortly after the daily observation at $48 \mathrm{hpf}$, it would not be detected until the following day, classified as hatching at $72 \mathrm{~h}$ and possibly as delayed. Therefore, in order for this potentially relevant and useful endpoint to be included in ENM testing, the protocol requires updating to be less ambiguous and more rigorous in its approach. This could include more frequent observations when assessing hatching or a separate experiment assessing these sublethal endpoints.

\section{Growth and morphological abnormalities}

Somatic growth and morphometrics have long been utilised as sublethal markers of toxicity in fish for traditional chemical substances (Schlenk et al. 2008; Groh et al. 2015) and are beginning to be used for ENMs (e.g., Ramsden et al. 2009; Bai et al. 2010a, b; Fraser et al. 2011; Clemente et al. 2014). The significant decrease in larvae length following exposure to Ag ENMs along with the absence of such effects in $\mathrm{TiO}_{2}$ ENM exposed animals indicates that body length measurements are ENM-specific, which may aid the differentiating of the effects of one material from another in hazard assessment.

During the course of the current work, it was seen that careful handling of larvae for morphometrics was crucial, particularly when euthanising remaining fish and placing them into fixative. Artefacts such as curved spine or even a disintegration of the body would occur if this was not done correctly and with care. Therefore, the inclusion of a suitable standard operating procedure into future TG would be essential, in order to ensure that the data are robust and comparable, the fundamental rationale behind the MAD principle.

The results from the present work suggest that morphometrics may be considered a valid approach for assessing the sublethal effects of some ENMs with comparable effects seen in other studies (e.g., multi-walled carbon nanotubes, Liu et al. 2014; silica ENMs, Duan et al. 2013; ZnO ENMs, Bai et al. 2010a, b), though one must be aware that similar effects have been seen with dissolved contaminants (e.g., reduced larval length in zebrafish larvae exposed to dissolved $\mathrm{Cu}$, Johnson et al. 2007). These measurements cannot therefore be considered nano-specific biomarkers for the toxic effects in fish, but nonetheless remain useful indicators of ENM toxicity. Differences in fish length and yolk sac volume during the current study showed the utility of these endpoints and should be incorporated into any prospective SOPs, but muscle block width was not a sensitive endpoint for any of the materials tested in the current study.

\section{Are the uses of the NOEC and LOEC endpoints still valid?}

As part of the reporting procedure, the TG requires the no observed effect concentration (NOEC) and the lowest observed effect concentration (LOEC). Due to the methods used in their calculation, these metrics are essentially a function of test chemical concentration, data variability, significance level (e.g., $95 \%$ ) and sample size (Warne and van Dam 2008). As such they have been criticised for their statistical flaws (e.g., Skalski 1981), which can result in them being poor estimators of safe chemical concentrations and incapable of producing consistent summary statistics (Crane and Newman 2000). There have been 
numerous calls for the cessation of their use in regulatory toxicology and even their reporting in peer-reviewed journals (e.g., Laskowski 1995; Chapman et al. 1996; Warne and van Dam 2008; Landis and Chapman 2011; SánchezBayo 2012). Clearly, this has not been implemented as the requirement for these metrics remains in use internationally, as seen here in the OECD 210 test. This is despite an OECD workshop in 1998 concluding that NOECs should be phased out, a view echoed by the International Organisation for Standardization (ISO) and the European Chemicals Agency (ECHA) (Jager 2012). The concerns that reduce their worth for traditional chemicals may be magnified when testing ENMs. For example, the issue of variability in the data which appears a far greater problem in tests with ENMs than traditional chemicals. Whilst it is outside the scope of the current work to suggest alternatives to these endpoints, there is clearly the need for an agreement and implementation of viable replacements.

\section{When should the exposures commence?}

The OECD 210 TG recommends that: The test should start as soon as possible after the eggs have been fertilised and preferably being immersed in the test solutions before cleavage of the blastodisc commences, or as close as possible after this stage. Cleavage of the blastodisc occurs between $3 / 4$ and $21 / 4 \mathrm{hpf}$ in zebrafish (Kimmel et al. 1995). Logistically speaking, this is a narrow window of opportunity in which to set up and commence the experiments. During the current work, concerns were raised that processing the several hundred eggs required to fulfil the additional treatments needed in the design (e.g., bulk materials, metal salt controls, dispersant controls) compromised accuracy. For example, working with haste to get the experimental vessels set up quickly after the eggs are fertilised may result in random human error, such as non-viable embryos being added to the experimental beakers. At best, this would introduce variance, and at worst could skew survival data (i.e., giving a false negative). Therefore, although survival in the control beakers was over that required for validation in OECD 210 (i.e., > $75 \%$ post-hatch throughout), a separate study was conducted to assess the worth of beginning the exposure as described in the current TG.

With a minimum of 20 embryos per beaker, a routine ENM experiment using the old OECD TG (OECD 1992a) required 660 viable embryos to fulfil OECD 210 criteria (five concentrations of the ENM in triplicate, five concentrations of an appropriate bulk or metal salt control in triplicate and three control beakers). Therefore, for this assessment on the time to start exposures, 660 embryos between $3 / 4$ and $21 / 4$ hpf were graded into 33 beakers (as per experimental conditions, $n=20$ embryos per beaker) and observed daily until hatched. However, hatching success ranged from 35 to $75 \%$ (data not shown) even though they were all in clean dechlorinated Plymouth tap water with more than adequate water quality and a low biomass loading. An identical experiment was then carried out using a new batch of embryos from the same brood stock, except that grading began when the eggs were at the $8-16$ cell stage. This increased hatching success to $95-99 \%$ in clean water (data not shown). This improvement in hatching is clearly due to being able to firmly identify viable embryos at the 8-16 cell stage and exclude poor embryos from the experimental design. The variance introduced by the initial selection of the embryos under the current TG will be dependent upon batch quality and experience of the worker, and raises concerns about the utility of this guideline for chemicals generally. Scoring embryos at the $8-16$ cell stage removes most of this uncertainty and could be incorporated into the new OECD 210 TG (OECD 2013); especially, now the revised test method is indicating a minimum of four replicates per treatment. This increase in replicates from three to four would add logistical pressure (speed vs. reliability) to the task of preparing test vessels with animals (e.g., 44 beakers containing 880 animals here), with further increases when solvent controls are necessary.

Some studies have observed an increased sensitivity in embryos exposed prior to hardening of the chorion compared to embryos that were exposed a little later when the chorion has hardened (e.g., zebrafish embryos exposed to wastewater, Gellert and Heinrichsdorff 2001). This was attributed to the reduced permeability of the chorion posthardening, and therefore, the authors argue that exposure should commence prior to the hardening (approximately $<0.5 \mathrm{hpf}$ ). This could be considered an environmentally realistic approach as fish embryos in the wild could be exposed at any point during their lifespan, but as described above, this would not be logistically practical with tests involving ENMs. Other workers have advocated dechorionation prior to exposure as a legitimate way to bypass the protective effects of the chorion and assess direct effects to the animal (e.g., Mizell and Romig 1997). However, although this approach may be suitable for proof of principle experiments (i.e., how does a substance affect an embryo without a barrier that may not be ubiquitously protective), it would not be appropriate for regulatory toxicity tests where many different test substances need to be screened, a problem that is exacerbated by the myriad of surface functionalisations available for ENMs. Furthermore, chemical dechorionation has been seen to result in low levels of survival, as low as $20 \%$ in zebrafish embryos incubated in pronase (Henn and Braunbeck 2011). Mechanical dechorionation is feasible, but impractical in embryos $<8 \mathrm{hpf}$, again due to variable survival rates (Henn and Braunbeck 2011). Mechanical dechorionation is also labour intensive and requires skill in order to prevent harm to the embryo. 


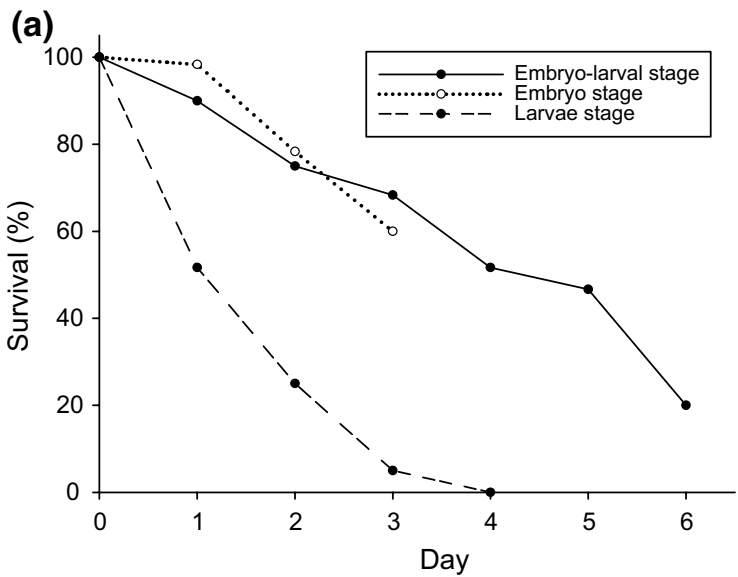

Fig. 4 A life-stage comparison experiment investigating the differences in survival of zebrafish embryos and larvae exposed to either a $58 \mu \mathrm{g}^{-1} \mathrm{Ag}$ ENMs or b $5 \mu \mathrm{g}^{-1} \mathrm{AgNO}_{3}$ for $96 \mathrm{~h}$. These values represented the previously determined 6 day $(144 \mathrm{~h}) \mathrm{LC}_{50}$ values for early-life stage zebrafish. Error bars and statistics are omitted for

\section{Is a test spanning both the embryonic and larval stages of fish development suitable for use with ENMs?}

The OECD 210 TG involves exposing the fish from fertilisation through hatching, the subsequent eleutheroembryo and larval stages, until the control fish reach a juvenile life stage. However, using a test spanning, these life stages can cause uncertainty in the interpretation of the data, as it has often been seen that the embryonic stage is less sensitive to chemicals than that of hatched larvae (e.g., cadmium, Eaton et al. 1978; copper, McKim et al. 1978a, b) or dechorionated embryos (e.g., silver, Guadagnolo et al. 2001). In order to maximise the efficiency and scientific value of the test, it is necessary to know whether this joint life-stage approach is valid for ENMs. Therefore, experiments were conducted to assess the sensitivity of pre-hatch embryos versus post-hatched larvae to ENMs along with animals that were exposed through both life stages. To this end, three experimental groups were exposed in triplicate to either $58 \mu \mathrm{g}^{-1} \mathrm{Ag}$ ENMs or a further three to $5 \mu \mathrm{g} \mathrm{l^{-1 }}$ $\mathrm{AgNO}_{3}$ (these values were the $144 \mathrm{~h} \mathrm{LC}_{50}$ values previously determined for early-life stage zebrafish for each material, respectively, Table 2). Group 1 were exposed to Ag ENMs or $\mathrm{AgNO}_{3}$ from $4 \mathrm{hpf}$ until free feeding (144 h). Group 2 were exposed to $\mathrm{Ag}$ ENMs or $\mathrm{AgNO}_{3}$ from $4 \mathrm{hpf}$ until hatching (approximately $48 \mathrm{~h}$ ). Group 3 were exposed to $\mathrm{Ag}$ ENMs or $\mathrm{AgNO}_{3}$ from hatching (4 hph) for $96 \mathrm{~h}$. The exposures were carried out using an identical experimental design to that describe above for the unmodified OCED 210 test with appropriate no added Ag and dispersant (NM300K-Dis) controls.

The results showed that larvae were more sensitive than embryos to both $\mathrm{Ag}$ ENMs and $\mathrm{AgNO}_{3}$, though this

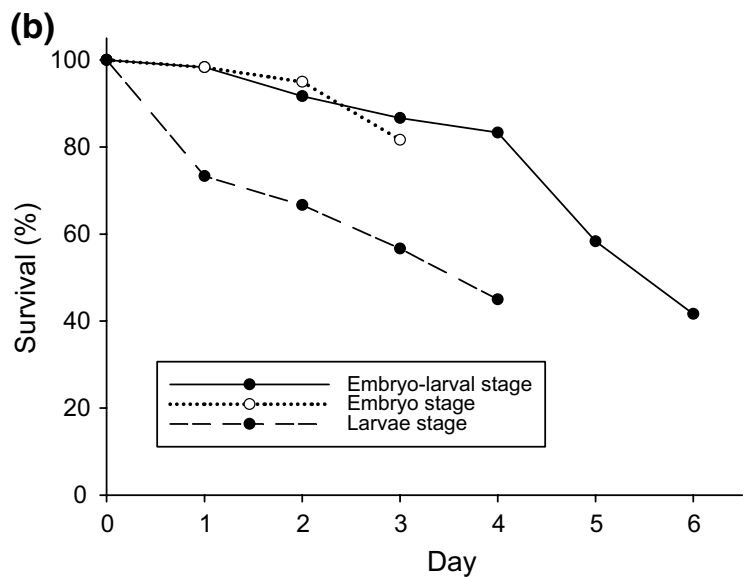

clarity, but there was a statistically significant difference (ANOVA, $P<0.05$ ) in survival between embryos and larvae at every time point in the Ag ENM exposure (a). Data are mean of triplicate beakers, $n=20$ embryos or larvae per beaker, 60 per treatment

was more noticeable in the Ag ENM treatment (Fig. 4). After $96 \mathrm{~h}$, there were no surviving larvae following exposure to Ag ENMs from post-hatching only, whereas larvae that were exposed to Ag ENMs from $4 \mathrm{hpf}$ throughout the embryonic stage first experienced approximately $25 \%$ survival after being hatched for $96 \mathrm{~h}$ (Fig. 4a). These results indicate that pre-exposure to Ag ENMs during the embryonic stage reduces sensitivity in hatched larvae or at least delays the effects. However, a similar trend was not seen in fish exposed to $\mathrm{AgNO}_{3}$, with larvae from both experimental groups experiencing similar levels of survival (around 40-45\%) after being exposed for $96 \mathrm{~h}$ post-hatching (Fig. 4b). Interestingly, embryos were not appreciably affected by exposure to $\mathrm{AgNO}_{3}$ from fertilisation, whilst embryos exposed to Ag ENMs did see some mortality prior to hatching (survival less than $80 \%$ in embryos exposed to Ag ENMs by $72 \mathrm{~h}$, compared to over $90 \%$ in those exposed to $\mathrm{AgNO}_{3}$ by that time point, Fig. 4).

Clearly these data highlight the need to carefully consider the rationale for conducting a joint embryo-larvae test. Whilst a shift towards the use of fish embryos as 'alternative' test organisms has been driven by ethical considerations to reduce the number of free-living vertebrate animals used in toxicity testing (Embry et al. 2010; Halder et al. 2010; Knöbel et al. 2012), this should not be at the risk of increased uncertainty in the process of hazard and risk assessment (Oris et al. 2012). Moreover, the OECD 210 test continues until the juvenile stage and therefore does not necessarily fit the 3Rs criteria in any case. Zebrafish embryos were sensitive to Ag ENMs here, but far less so than larval fish. The inclusion of the embryo stage also has implications for experimental design in tests with ENMs. For example, if the ENMs aggregate and fall out of 
suspension, those embryos on the bottom of the tanks or beakers are likely to be smothered, and whilst this may represent a novel mechanical mechanism of toxicity to fishes, it also implies that one should not assume that the toxicity reported in a test is solely attributable to chemical toxicity. Therefore, the use of embryos in ENM toxicity testing may have some merit, but it is debatable whether they are a more useful life stage than the larval stage. These data also highlights the difficulty in conducting reproducible toxicity tests with ENMs using the unmodified OECD 210 TG. A previously determined $\mathrm{LC}_{50}$ value using the OECD 210 method (Table 2) was used for the exposure concentrations in the life-stage study. However, this concentration caused $100 \%$ mortality after 96-h exposure in the larvae treatment, an effect not seen in animals exposed to the relevant $\mathrm{LC}_{50}$ concentration of $\mathrm{AgNO}_{3}$ (Fig. 4).

\section{Approaches for maintaining ENM exposure}

In the present study, maintaining the exposure concentration of the ENMs was problematic when using the current, unmodified, OECD 210 TG. Two predominant issues in aqueous toxicity tests with ENMs are the loss of the materials from solution (e.g., settling out, adhering to tank/beaker walls) and technical limitations in analytical procedures to quantify the ENMs in samples. The difficulties involved in the quantification of ENMs are well documented (see Handy et al. 2008, 2012b; Tiede et al. 2008; Simonet and Valcárcel 2009; von der Kammer et al. 2012; Shaw et al. 2013), and the development of suitable analytical techniques is beyond the scope of the current work. However, modifications to test criteria and ways of improving the maintenance of exposure concentrations were explored.

\section{Redefine test criteria}

Prior to investigating potential changes to test apparatus and protocols, the first consideration is whether a relaxation of the criteria required to validate the test with respect to maintaining the exposure should be made. In the case of ENMs, it is arguable that some relaxation of the criteria may be pragmatic, to ensure that the necessary testing is not delayed. Although the updated OECD 210 TG (OECD 2013) does have provisions for when the data do not test requirements for the exposure, it remains critical that attempts should be made to ensure ENM dispersions in toxicity tests. Therefore, attempts were made to improve this aspect of the test design, with our approach considering the importance of keeping the methodology relatively simple in order to allow routine use within an ecotoxicology contract testing laboratory environment. The strategy included the use of dispersants in test water, stirring and the development of exposure chambers (see below). Initially, these experiments were conducted without fish in order to try and improve the colloidal suspensions and later with embryos and larvae to assess the effect of the presence of the animals on the dispersion. $\mathrm{TiO}_{2}$ ENMs were initially chosen as the test material as they had proven the most problematic in terms of maintaining the exposure concentration in the previous experiments, though further work included Ag ENMs and MWCNT (see below).

\section{Changes to exposure media}

A common approach for maintaining ENMs in solution is with the use of dispersants (see Handy et al. 2012a, b; Shaw et al. 2013). During the current experiments, three different dispersing agents were tested: sodium dodecyl sulphate (SDS), Triton X-100 and citrate. However, the only ENM to show an improvement was MWCNT when $0.25 \mathrm{mg} \mathrm{l}^{-1} \mathrm{SDS}$ was added, though this was not quantifiable due to technical constraints. The addition of $2 \%$ Triton $\mathrm{X}-100$ not only failed to improve dispersions of the ENMs, but it also resulted in the exposure media being too viscous to support fish life. It is possible that as the Ag ENMs used here (NM-300K) were already mixed with a dispersant media (NM-300K-Dis); this negated any potential effects of the other dispersants. This last point demonstrates the importance of understanding the full constituents of the ENMs to be tested, with capping agents potentially affecting the experimental design. Although there are other dispersants that may be more effective, it is unlikely that many of those used will provide suitable husbandry conditions to sustain healthy aquatic life (Petersen et al. 2015). Another approach is to use naturally occurring substances. For example, natural organic matter (NOM) has been seen to improve ENM dispersions (Zhang et al. 2009; Delay et al. 2011), but increasing NOM in an aqueous fish test will not inform upon possible effects in an environment where levels are naturally low. When considering all of these issues, it is preferable to avoid the use of dispersants in tests with ENMs.

\section{Mixing to improve ENM dispersion}

With the use of dispersing agents undesirable, the next approach was to attempt to improve ENM dispersion by use of mechanical mixing in the experimental beakers. A preliminary experiment was carried out to assess the ability to keep the $\mathrm{TiO}_{2}$ ENMs in suspension over a 24-h period by simple stirring (12-mm stirring bars on a magnetic multipoint stirring plate (5.5 MOT $\mathrm{min}^{-1}$, RO 15 IKA-Werke). Triplicate test beakers containing $300 \mathrm{ml}$ of dechlorinated Plymouth tap water in 400-ml beakers (as used in animal exposures) were dosed with either 10 or $160 \mathrm{mg} \mathrm{l}^{-1} \mathrm{TiO}_{2}$ 
ENMs. Samples analysed by ICP-OES 24-h post-dosing showed that the measured mid-water column concentration of $\mathrm{TiO}_{2}$ from the $10 \mathrm{mg} \mathrm{l}^{-1} \mathrm{TiO}_{2} \mathrm{ENM}$ treatment was $63 \%$ of the nominal exposure concentration when it was stirred. Interestingly, in the unstirred beakers, just $5 \%$ of the nominal dose was quantified, meaning there was an almost 13-fold increase with stirring. However, when the $160 \mathrm{mg} \mathrm{l}^{-1}$ treatment was assessed, the results were less prominent. Here, the measured exposure concentrations $24 \mathrm{~h}$ post-dosing were 27 and $6.5 \%$ of the nominal concentrations with and without stirring, respectively. This indicated that although stirring was able to improve dispersion of $\mathrm{TiO}_{2}$ ENMs, it was mass concentration dependent. It is notable, however, that this was using a high $\mathrm{TiO}_{2}$ ENM concentration $\left(160 \mathrm{mg} \mathrm{l}^{-1}\right.$ ), which is far higher than the highest recommended concentration in OECD 210 $\left(10 \mathrm{mg} \mathrm{l}^{-1}\right)$.

From the view point of logistics for a testing laboratory, the initial aim was to enable sufficient mixing of the ENMs so that daily water changes were not required to maintain the exposure. However, this was not possible, as even with stirring, the measured concentration of $\mathrm{TiO}_{2}$ ENMs decreased over $24 \mathrm{~h}$ with aggregates clearly observed to settle at the bottom of the stirred beakers in the $160 \mathrm{mg} \mathrm{l}^{-1}$ treatment. Using larger $(20 \mathrm{~mm})$ stirring bars partially resolved this problem, visually showing an improved dispersion of $\mathrm{TiO}_{2}$ ENMs at both nominal concentrations, with no discernible settling of $\mathrm{TiO}_{2}$ on the bottom of the beaker (data not shown).

\section{Exposure chambers}

Fish larvae are delicate animals, and although stirring was effective at improving the colloidal suspension of $\mathrm{TiO}_{2}$ ENMs in the exposure beakers, it also created a mechanical injury hazard to the organisms. There are also concerns that forcing a larva to swim in the vortex of mechanically stirred beaker would change the energy partitioning in the animal (i.e., higher cost of swimming). This may result in less energy being available to deal with toxicity (Handy et al. 1999), thus inadvertently increasing the stress on the animals. Consequently, several modifications of the test apparatus were explored in attempts to find a way of healthily maintaining the animals in the water column of the beaker from the perspective of animal welfare, whilst also finding a stirring method that could still be utilised. In separate experiments within our laboratory, Boyle et al. (2015) attempted to solve this issue by the use of exposure chambers based upon a modification of methods for suspended sediment experiments. In their study, the use of exposure chambers in 2-1 beakers with aeration resulted in significantly increased the quantifiable concentrations of $\mathrm{Cu}, \mathrm{TiO}_{2}$ and Ag ENMs. These improved dispersions consequently resulted in lower $\mathrm{LC}_{50}$ values for each ENM tested and negated the need for daily water changes. However, for the current study, it was decided that although this was a good model to follow, in order to conduct multiple exposures simultaneously, the beaker volume (thus size) needed to be reduced. Initial experiments in the current study used fully filled $400-\mathrm{ml}$ beakers, but whilst these were a convenient size with which to work, the amount of the dose measured by ICP-OES did not significantly increase (data not shown). Further experiments revealed that using a 1-1 beaker (filled to the 1-1 mark) resulted in a significant increase in the measured $\mathrm{TiO}_{2} \mathrm{ENM}$ concentration in the test vessels towards the desired nominal value. Though the 1-1 beakers still had slightly lower $\mathrm{TiO}_{2}$ levels than that seen in 2-1 beakers, there was far less variability. For example, the $24 \mathrm{~h}$ measured concentration of a $10 \mathrm{mg} \mathrm{l}^{-1} \mathrm{TiO}_{2}$ ENM dose was $80.0 \pm 8.7$ and $83.8 \pm 16.6 \%$ of the nominal concentration for the 1- and 2-1 chambers, respectively (data are mean $\pm \mathrm{SD}, n=12$ beakers per treatment). Further attempts to maintain this for $96 \mathrm{~h}$, with and without aeration, were unsuccessful (data not shown), and it was decided that daily water changes were still a necessity.

These experiments led to the development of a prototype exposure chamber similar to that of Boyle et al. (2015). The chamber was made of polyvinyl chloride plastic (PVC) and allowed water flow, but also protected the animals from mechanical injury. These chambers (one per beaker) were suspended in the water column and had meshed cover apertures strategically placed to allow inwards and outwards flow of the ENMs (Fig. 5). The chambers essentially work via a stirring bar that creates a flow of water up through the water column at the sides of the beaker and then down through the chamber back towards the vortex, thereby evenly circulating the dispersed $\mathrm{TiO}_{2}$ ENMs around the beaker. The initial mesh used was constructed from nylon and was designed for aquarium use (e.g., fish netting). It had a pore size of $441.0 \pm 26.8 \mu \mathrm{m}$ (mean $\pm \mathrm{SD}, n=6$ images), chosen so that neither the embryos nor the larvae could fall or escape through it, but big enough to allow even large aggregates of ENMs to flow through. During these experiments, it was noticed that the speed of stirring that was effective in the original experiments without chambers was no longer optimum. Reducing the speed to 3.5 MOT $\mathrm{min}^{-1}$ in conjunction with the prototype exposure chamber improved the stability of the exposure concentration (data not shown).

Experiments were then conducted using both embryos and larvae, and it was seen that the presence of the chamber and the mesh size was suitable for housing the embryos and larvae with no mechanical damage from the stirring bars or escapees. Furthermore, the animals were not affected by the water flow, and quiescent behaviour was observed as normal for early life stage zebrafish (i.e., not discernibly 
Fig. 5 Diagrammatic representation of the exposure chambers (a) used to improve the dispersion of ENMs in the test [based upon Boyle et al. (2015)]. Using this design in conjunction with magnetic stirrers improved ENM dispersion in the experimental beakers and therefore the exposure, whilst also maintaining animal health. The chamber was effective for both embryos and larvae. The dimensions of the chamber were: height $125 \mathrm{~mm}$, diameter $68 \mathrm{~mm}$, wall thickness $2 \mathrm{~mm}$, diameter of mesh-covered aperture on the side of the chamber $45 \mathrm{~mm}$. c, d Micrographs of the two types of mesh employed in the exposure chambers following 6-h exposure to $10 \mathrm{mg}^{-1}$ $\mathrm{TiO}_{2}$ ENMs with stirring. Nylon mesh (b) remained relatively free of $\mathrm{TiO}_{2}$ ENMs, whilst PTFE-coated mesh (c) had visible aggregates of $\mathrm{TiO}_{2}$ ENMs (arrows) which blocked the pores (Olympus SZX7 with Infinity $2-2 \mathrm{C}$ camera, $\times 4.0$ magnification)

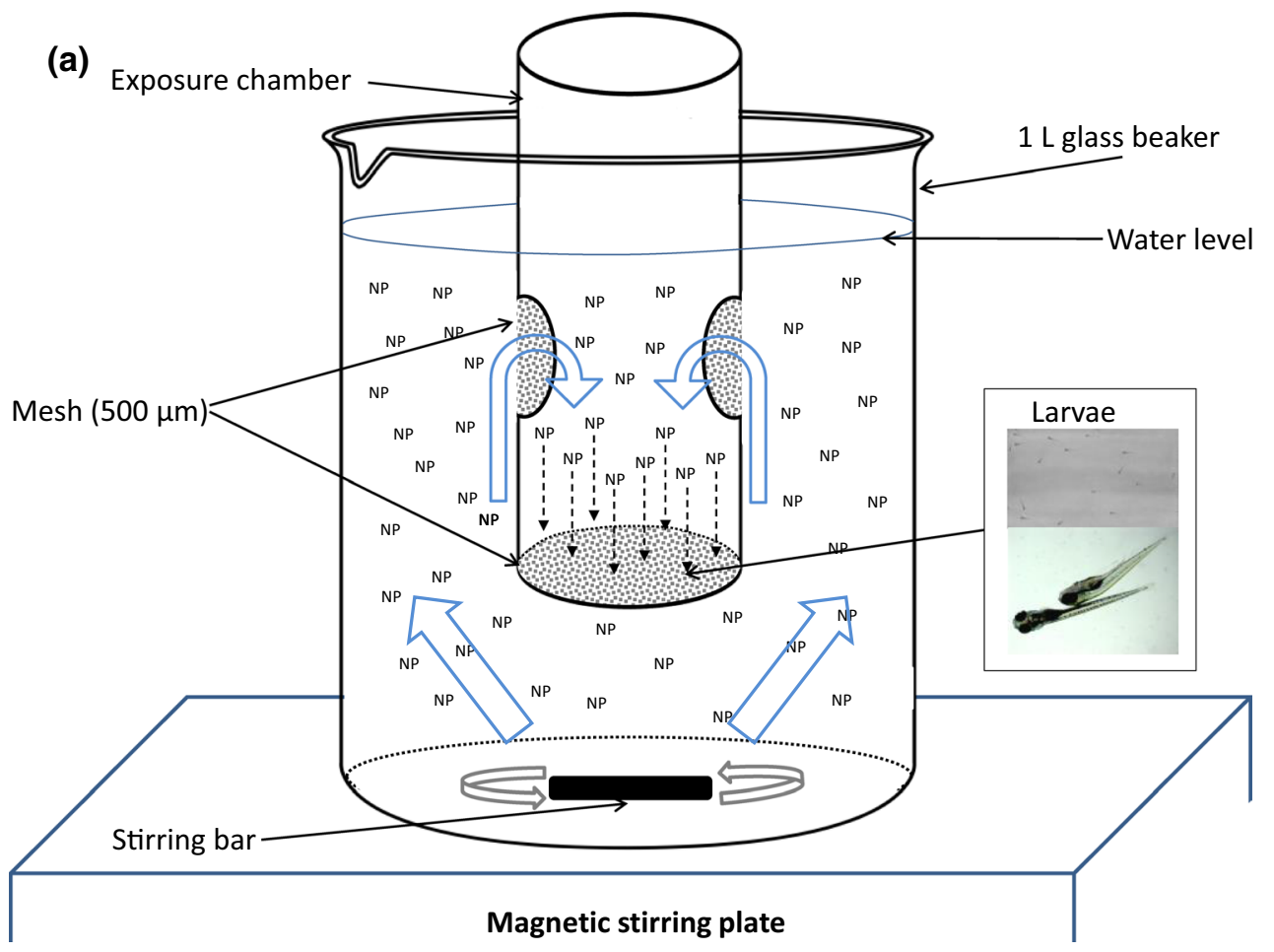

(b)

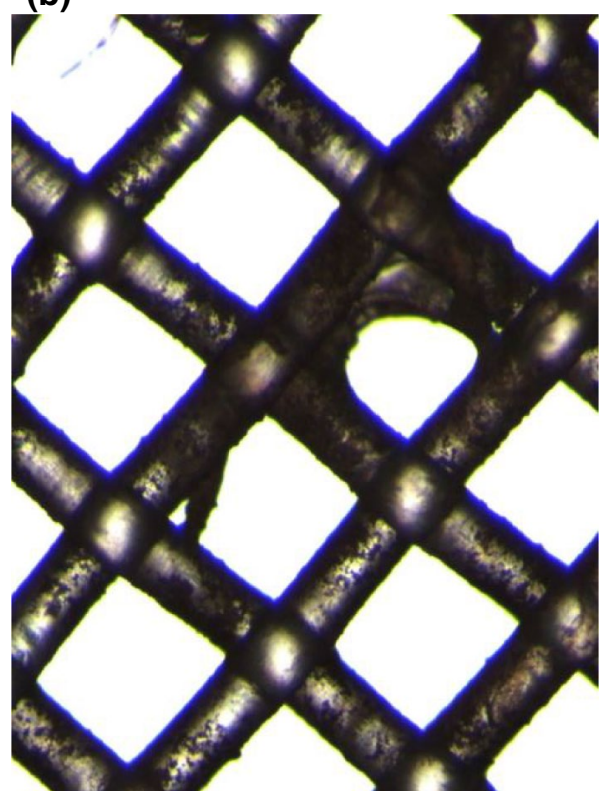

(c)

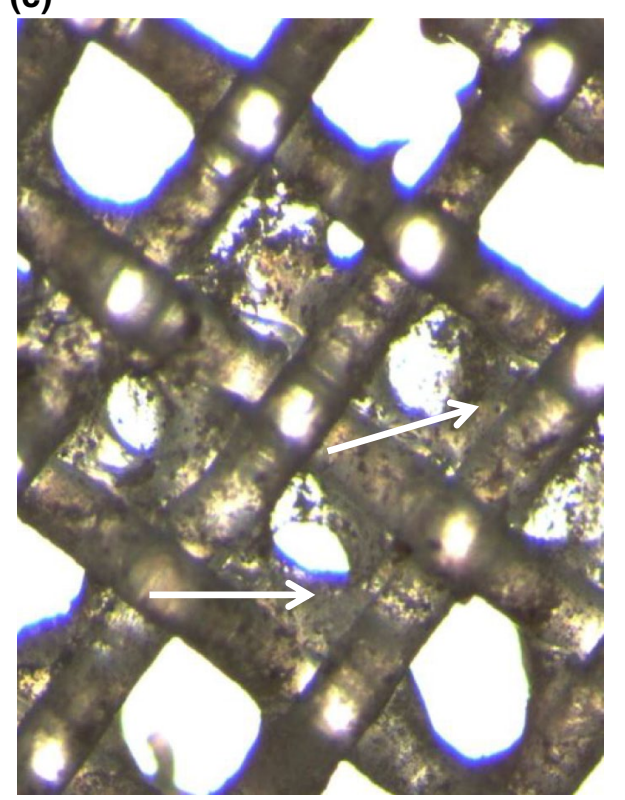

different from larvae in control beakers with no stirring). Further attempts were made to improve the dispersion of $\mathrm{TiO}_{2}$ ENMs within the chambers by exploring increased mesh size and material and changing the chamber vessels from PVC to borosilicate glass (i.e., to reduce adsorption of the test substance to the apparatus). It was hypothesised that polytetrafluoroethylene (PTFE)-coated mesh would improve the consistency of the exposure as this material is known for its 'non-stick' properties (e.g., Teflon). However, measured concentrations of $\mathrm{TiO}_{2}$ ENMs were actually reduced when using PTFE mesh compared to nylon (data not shown). A microscopic analysis of the different mesh types revealed that the $\mathrm{TiO}_{2}$ ENMs had aggregated and blocked the pores of the PTFE-coated mesh, far more than seen in the nylon mesh (Fig. 5b, c).

To assess the efficacy of the exposure chambers, that is, its ability to maintain homogenous dispersions of the test materials, an experiment was carried out where nominal 
concentrations of $\mathrm{TiO}_{2}$ and $\mathrm{Ag}$ ENMs (with suitable controls) were added (in triplicate) to 1-1 beakers either with or without a chamber. Samples were taken $10 \mathrm{~min}$ post-dosing (designated as $0 \mathrm{~h}$ ) and at $24 \mathrm{~h}$ and assessed for Ti or Ag as appropriate using the methods described above. The results clearly show the benefits of using the chambers, with notable improvements in the maintenance of exposure concentrations over $24 \mathrm{~h}$ compared to static beakers (Fig. 6). To further explore the use of the exposure chambers, an experiment was conducted using MWCNT. Though it is not yet possible to quantify MWCNT in solution, it was apparent that when using a chamber and stirring, a concentration of $10 \mathrm{mg} \mathrm{l}^{-1}$ MWCNT did not settle out of suspension as noticeably as when added to a static beaker without mixing. This demonstrates the utility of the apparatus for ENMs with different physico-chemical properties and shape to that of $\mathrm{TiO}_{2}$ and Ag ENMs.

It is essential that methods used in regulatory toxicology have good reproducibility, and so, the utility of the exposure chambers was assessed for variability with both $\mathrm{TiO}_{2}$ and Ag ENMs. Here, the lowest and highest concentrations of $\mathrm{TiO}_{2}$ ENMs, $\mathrm{TiO}_{2}$ bulk, $\mathrm{Ag}$ ENMs and $\mathrm{Ag}\left(\right.$ as $\mathrm{AgNO}_{3}$ ) used in the original exposures (Table 1) were added to chambers in beakers $(n=6$ chambers/beakers per treatment/material) containing 11 of Plymouth tap water as before. Water samples were taken from the centre of each chamber at 0 and $24 \mathrm{~h}$, and assessed by ICP-MS $\left(\mathrm{AgNO}_{3}\right)$ and ICP-OES $\left(\mathrm{TiO}_{2}\right.$ ENMs and bulk, Ag ENMs) as described previously. Six samples per test material were assessed, and the coefficient of variation (CV) between each set of six was calculated. The CV provides information on the similarity of the measured concentrations, with low and high variance indicating good and poor reproducibility, respectively. The variation was significantly lower when the exposure chambers were used (Table 7) compared to the original exposures using the unmodified TG (Tables 3, 4). For example, 10 min post-dosing, the $\mathrm{CV}$ ranged from approximately 21-41 and 14-32\% for $\mathrm{TiO}_{2}$ ENMs and Ag ENMs, respectively, without chambers. However, when the exposure chambers were used the $\mathrm{CV}$ decreased to approximately 3-10 \% for $\mathrm{TiO}_{2}$ ENMs and 2.5-5\% for the Ag ENMs, also at $10 \mathrm{~min}$ after dosing. This becomes even more significant $24 \mathrm{~h}$ after dosing, where the $\mathrm{CV}$ was between 71 and $90 \%$ for $\mathrm{TiO}_{2}$ ENMs and 15-37\% for Ag ENMs without chambers, compared to 6-12 and 3-8\% for $\mathrm{TiO}_{2}$ and $\mathrm{Ag}$ ENMs, respectively, with a chamber.

Finally, the use of glass chambers rather than PVC was examined and this change in material increased the measured concentration from $7.5 \pm 0.9$ to $8.9 \pm 0.7 \mathrm{mg} \mathrm{l}^{-1}$ (data, mean $\pm \mathrm{SD}, n=10$ beakers per treatment) for a nominal $\mathrm{TiO}_{2}$ ENM concentration of $10 \mathrm{mg} \mathrm{l}^{-1}$ after $24 \mathrm{~h}$ compared to PVC chambers. This represents an almost $15 \%$, improvement towards the
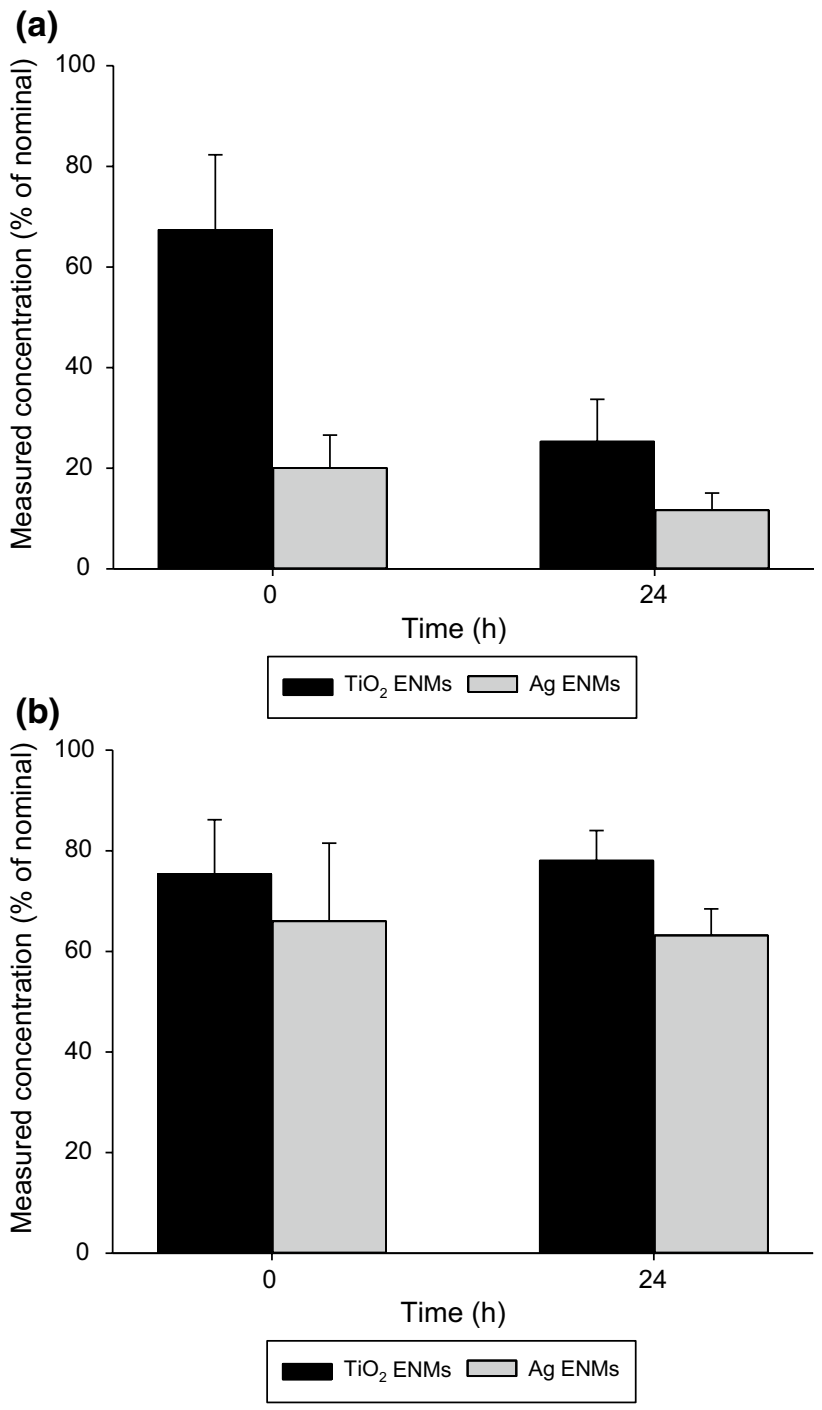

Fig. 6 Measured concentrations of both $\mathrm{TiO}_{2}$ ENMs and Ag ENMs decreased over time without exposure chambers (a), and significantly improved over $24 \mathrm{~h}$ when glass exposure chambers were used with nylon mesh (b). The $\mathrm{TiO}_{2}$ ENM nominal concentration was $10 \mathrm{mg} \mathrm{l}^{-1}$, whilst the nominal concentration of the $\mathrm{Ag}$ ENMs was $50 \mu \mathrm{g} \mathrm{1^{-1 }}$

target concentration during this particular experiment, though previous experiments with PVC chambers had resulted in higher measurable concentrations of $\mathrm{TiO}_{2}$ ENMs (e.g., Table 7).

Together, these data show that the chambers were not only able to produce measured exposure concentrations closer to nominal than the original TG, but also reduced inter-beaker variability. Furthermore, they alleviated handling stress on the animals (refinement of animal welfare) by facilitating the quick and easy removal of the fish from the test beakers when conducting water changes. This also reduced the duration of the task, thus improving the logistics (important for commercial testing laboratories). 
Table 7 Utility and precision of the exposure chambers for maintaining $\mathrm{TiO}_{2}$ and $\mathrm{Ag}$ ENM dispersion over $24 \mathrm{~h}$

\begin{tabular}{|c|c|c|c|c|c|c|c|}
\hline Material & $\begin{array}{l}\text { Nominal concentra- } \\
\text { tion }\end{array}$ & $\begin{array}{l}\text { Measured concentra- } \\
\text { tion at } 0 \mathrm{~h}\end{array}$ & $\begin{array}{l}\text { Percentage of nomi- } \\
\text { nal at } 0 \mathrm{~h}\end{array}$ & $\mathrm{CV}$ & $\begin{array}{l}\text { Measured concentra- } \\
\text { tion at } 24 \mathrm{~h}\end{array}$ & $\begin{array}{l}\text { Percentage of nomi- } \\
\text { nal at } 24 \mathrm{~h}\end{array}$ & $\mathrm{CV}$ \\
\hline & $\left(\mathrm{mg} \mathrm{l}^{-1}\right)$ & $\left(\mathrm{mg} \mathrm{l}^{-1}\right)$ & $(\%)$ & $(\%)$ & $\left(\mathrm{mg} \mathrm{l}^{-1}\right)$ & $(\%)$ & $(\%)$ \\
\hline $\mathrm{TiO}_{2}$ ENMs & 10 & $8.4 \pm 0.3$ & 83.5 & 3.4 & $7.4 \pm 0.4$ & 73.6 & 5.7 \\
\hline $\mathrm{TiO}_{2}$ ENMs & 160 & $119.9 \pm 8.2$ & 75.0 & 6.8 & $101.9 \pm 12.5$ & 63.7 & 12.3 \\
\hline $\mathrm{TiO}_{2}$ bulk & 10 & $7.3 \pm 0.5$ & 72.9 & 6.5 & $6.4 \pm 0.4$ & 63.6 & 6.4 \\
\hline $\mathrm{TiO}_{2}$ bulk & $\begin{array}{l}160 \\
\left(\mu g 1^{-1}\right)\end{array}$ & $\begin{array}{l}112.4 \pm 11.2 \\
\left(\mu \mathrm{g}^{-1}\right)\end{array}$ & $\begin{array}{l}70.3 \\
(\%)\end{array}$ & $\begin{array}{l}10.0 \\
(\%)\end{array}$ & $\begin{array}{l}97.4 \pm 11.6 \\
\left(\mu \mathrm{g}^{-1}\right)\end{array}$ & $\begin{array}{l}60.9 \\
(\%)\end{array}$ & $\begin{array}{l}11.9 \\
(\%)\end{array}$ \\
\hline Ag ENMs & 50 & $45.2 \pm 2.1$ & 90.4 & 4.7 & $41.7 \pm 3.2$ & 83.4 & 7.7 \\
\hline Ag ENMs & 1000 & $761.8 \pm 39.0$ & 76.2 & 5.1 & $649.9 \pm 35.1$ & 64.9 & 5.4 \\
\hline $\mathrm{AgNO}_{3}$ & 2.5 & $2.4 \pm 0.07$ & 94.6 & 2.9 & $2.1 \pm 0.1$ & 84.2 & 5.0 \\
\hline $\mathrm{AgNO}_{3}$ & 50 & $48.8 \pm 1.2$ & 97.6 & 2.5 & $44.4 \pm 1.4$ & 88.7 & 3.2 \\
\hline
\end{tabular}

All samples were taken from the centre of the beaker and analysis was carried out using ICP-OES, data are mean \pm standard deviation, $n=6$ samples per treatment per time point, $\mathrm{CV}(\%)$ is the coefficient of variation, used to test the within treatment variability

In order to be fit for purpose for routine use, the exposure chambers should be standardised in terms of their dimensions, shape and material. The use of standardised exposure chambers could increase the consistency of the hazard data generated for ENMs (Petersen et al. 2015), which adheres to the MAD principle that these tests were originally designed to achieve.

\section{Recommendations and conclusions}

Our recommendations are presented in Table 6, based on our case study experiences at the bench with the $\mathrm{TiO}_{2}$ ENMs, Ag ENMs and MWCNT tested here. Overall, in its current form, the TG for OECD 210 was not entirely proven fit for purpose for ENMs and requires some modification. Some aspects of the TG for OECD 210 would benefit from further written technical guidance on ENMs, perhaps as supplementary appendices or by referring the reader to the detailed $\mathrm{TG}$ documents emerging from the Working Party for Manufactured Nanomaterials (WPMN) at the OECD. The most prominent recommendations from Table 6 with respect to the nano-specific problems with the test are:

1. A shift towards the use of larval rather than embryos in a much shorter test, as the larvae are more sensitive to ENMs. This recommendation also removes the confounding problem of multiple life-stage effects from the data interpretation (for all chemicals), as the current test design has embryonic fish and larval stages in one continuous test. The need for chronic ENM tests remains;

2. The utilisation of an exposure chamber (modification of the test apparatus) to maintain exposure concentrations during tests with ENMs rather than modifying the test criteria to a more lenient expected concentration of the nominal test substance concentration. The exposure chambers considerably improve the dispersion of the ENMs throughout the test vessels so that the current test criteria can be met;

3. Inclusion of written guidance on how to measure the sublethal endpoints in fish, and commentary on which endpoints seem sensitive to ENMs so far.

Table 6 also has several recommendations on the technical details of the OECD 210 TG that are aimed at standardising aspects that are important factors in the behaviour of ENMs, but not previously a worry for traditional chemicals. These include a preference to avoid the use solvents, being more prescriptive about when the test substance should be added, extra controls for ENMs, and when/how to feed fish so that it does not interfere with ENM characterisation in the test water. There are also recommendations that either add a comment or an appendix about stock dispersion and media preparation, or links that prompt the reader towards other TG documents from the WPMN where the information may be found for ENMs.

There are also a number of recommendations that are not necessarily nano-specific, but are a source of variation in the current OECD 210 method that can be improved upon by considering the biology of the fish (Table 6), for example, comments on the scoring of embryos at the start of a test. The scoring of embryos during the 8-16 cell stage drastically improved hatching success, and even if embryos are not used in the exposure, this subsequently improves the efficiency of a larval test. Shortening the test by using only a larval stage would be logistically beneficial to the testing laboratory. There is also scope to improve the artificial water recipes so that they are more physiological for fishes. 
Whilst these recommendations are intended to improve the utility of the test as a standardised method for hazard assessment, the opportunity to improve the environmental relevance and ethical aspects relating to animal welfare should be taken. Adding a benthic species to the list of organism will be beneficial for substances that settle from the water column in aquatic ecosystems. Proposing a shorter larvae-only style of test does not undermine the ecological importance of the data obtained. In polluted water, unhatched embryos have some protection from the chorion and buffering power of the perivitelline fluid, and consequently, there may be more environmental concerns about hatching itself, than the subsequent survival of the free swimming larvae. The normal development and survival of larvae are a critical part of recruitment into fish populations, and it is necessary to understand the potential effects of ENMs on these ecologically relevant processes (Handy et al. 2011). A larval-only test would reduce the use of animals (3Rs), but remain sensitive for hazard assessment purposes. For risk assessment, logic dictates that testing the most sensitive life stage will offer the greatest probability of protecting other life stages when the risk analysis is performed. For the Ag ENMs and to a lesser extent the MWCNT tested here, the hatched larvae were more sensitive than the unhatched embryos. There is ethical pressure to move towards embryo testing as an alternative to adult fishes. However, the scientific reasoning for using a particular life stage for hazard assessment needs to be clearly defined and weighed against the ethical concerns for the test organism. For our recommended larval test for ENMs, the first $24-48 \mathrm{~h}$ or so after hatching (depending on water temperature/animal species) is prior to first feeding and therefore outside of the licensing required under the current EU directives on animal welfare during scientific procedures.

In conclusion, the utility of the OECD 210 ELS test has been experimentally and critically evaluated using a case study approach involving several ENMs with different physico-chemical properties. There are concerns for using ENMs in the current unmodified test method, but these technical problems have been resolved with recommendations for improving the utility of the test for ENMs, as well as other sources of variation associated with the biology of the organisms and general test design. The ELS test using zebrafish (Danio rerio) remains a useful tool for hazard assessment, but our recommendations will improve the scientific robustness of the method as well as increasing the utility of the protocol from the view point of logistics and time in the laboratory. The experiments here were done with the regulatory toxicology community in mind, and it is hoped that regulatory bodies, such as the OECD, can consider these recommendations for adoption.
Acknowledgments This work was carried out as part of the E.C. MARINA Project, Call identifier: FP7-NMP-2010-LARGE-4, Grant Agreement No: NMP4-LA-2011-263215 (MARINA). The PI at Plymouth was Professor R. D. Handy. Dr Shaw organised and conducted the experiments at the bench, with assistance at specific times from temporary RAs at the bench, C.C. Liddle and K.M. Windeatt, who contributed equally. Shaw and Handy prepared this critical review and take responsibility for the scientific opinions herein. Thanks go to Dr. Andrew Fisher for help with ICP-OES and ICP-MS.

\section{References}

Al-Bairuty GA, Shaw BJ, Handy RD, Henry TB (2013) Histopathological effects of waterborne copper nanoparticles and copper sulphate on the organs of rainbow trout (Oncorhynchus mykiss). Aquat Toxicol 126:104-115

Al-Jubory AR, Handy RD (2013) Uptake of titanium from $\mathrm{TiO}_{2}$ nanoparticle exposure in the isolated perfused intestine of rainbow trout: nystatin, vanadate and novel $\mathrm{CO}_{2}$-sensitive components. Nanotoxicology 7:1282-1301

Asharani PV, Wu YL, Gong Z, Valiyaveettil S (2008) Toxicity of silver nanoparticles in zebrafish models. Nanotechnology 19:255102

Bai W, Zhang Z, Tian W, He X, Ma Y, Zhao Y, Chai Z (2010) Toxicity of zinc oxide nanoparticles to zebrafish embryo: a physicochemical study of toxicity mechanism. J Nanopart Res 12:1645-1654

Besinis A, De Peralta T, Handy RD (2014) The antibacterial effects of silver, titanium dioxide and silica dioxide nanoparticles compared to the dental disinfectant chlorhexidine on Streptococcus mutans using a suite of bioassays. Nanotoxicology 8:1-16

Bilberg K, Malte H, Wang T, Baatrup E (2010) Silver nanoparticles and silver nitrate cause respiratory stress in Eurasian perch (Perca fluviatilis). Aquat Toxicol 96:159-165

Bilberg K, Hovgaard MB, Besenbacher F, Baatrup E (2012) In vivo toxicity of silver nanoparticles and silver ions in Zebrafish (Danio rerio). J Toxicol Article ID 293784

Bird NC, Mabee PM (2003) Developmental morphology of the axial skeleton of the zebrafish, Danio rerio (Ostariophysi: Cyprinidae). Dev Dyn 228:337-357

Boyle D, Boran H, Atfield AJ, Henry TB (2015) Use of an exposure chamber to maintain aqueous phase nanoparticle dispersions for improved toxicity testing in fish. Environ Toxicol Chem 34:583-588

Brinkman SF, Hansen DL (2007) Toxicity of cadmium to early life stages of brown trout (Salmo trutta) at multiple water hardnesses. Environ Toxicol Chem 26:1666-1671

Bryson-Richardson R, Berger S, Currie P (2012) Atlas of zebrafish development. Elsevier, London 232

Celá P, Veselá B, Matalová E, Večeřa Z, Buchtová M (2014) Embryonic toxicity of nanoparticles. Cells Tissues Organs 199:1-23

Chae YJ, Pham CH, Lee J, Bae E, Yi J, Gu MB (2009) Evaluation of the toxic impact of silver nanoparticles on Japanese medaka (Oryzias latipes). Aquat Toxicol 94:320-327

Chapman PM, Caldwell, RS, Chapman PF (1996) A warning: NOECs are inappropriate for regulatory use. Environ Toxicol Chem 5: 77-79

Cheng J, Cheng SH (2012) Influence of carbon nanotube length on toxicity to zebrafish embryos. Int J Nanomed 7:3731-3739

Cheng J, Flahaut E, Cheng SH (2007) Effect of carbon nanotubes on developing zebrafish (Danio rerio) embryos. Environ Toxicol Chem 26:708-716

Christen V, Capelle M, Fent K (2013) Silver nanoparticles induce endoplasmatic reticulum stress response in zebrafish. Toxicol Appl Pharm 272:519-528 
Clemente Z, Castro VL, Feitosa LO, Lima R, Jonsson CM, Maia AH, Fraceto LF (2013) Fish exposure to nano- $\mathrm{TiO}_{2}$ under different experimental conditions: methodological aspects for nanoecotoxicology investigations. Sci Total Environ 463-464:647-656

Clemente Z, Castro VLSS, Moura MAM, Jonsson CM, Fraceto LF (2014) Toxicity assessment of $\mathrm{TiO}_{2}$ nanoparticles in zebrafish embryos under different exposure conditions. Aquat Toxicol 147:129-139

Crane M, Newman MC (2000) What level of effect is a no observed effect? Environ Toxicol Chem 19:516-519

Crane M, Handy RD, Garrod J, Owen R (2008) Ecotoxicity test methods and environmental hazard assessment for engineered nanoparticles. Ecotoxicology 17:421-437

Delay M, Dolt T, Woellhaf A, Sembritzki R, Frimmel FH (2011) Interactions and stability of silver nanoparticles in the aqueous phase: influence of natural organic matter (NOM) and ionic strength. J Chromatogr A 1218:4206-4212

Duan J, Yu Y, Shi H, Tian L, Guo C, Huang P, Zhou X, Peng S, Sun Z (2013) Toxic effects of silica nanoparticles on zebrafish embryos and larvae. PLoS ONE 8(9):e74606. doi:10.1371/journal.pone.0074606

Eaton JG, McKim JM, Holcombe GW (1978) Metal toxicity to embryos and larvae of seven freshwater fish species. I. Cadmium. Bull Environ Contam Toxicol 19:95-103

Embry MR, Belanger SE, Braunbeck TA, Galay-Burgos M, Halder M, Hinton DE, Léonard MA, Lillicrap A, Norberg-King T, Whale G (2010) The fish embryo toxicity test as an animal alternative method in hazard and risk assessment and scientific research. Aquat Toxicol 97:79-87

European Commission (2011) Commission recommendation of 18 October 2011 on the definition of nanomaterial. Official Journal of the European Union, (2011/696/EU)

Federici G, Shaw BJ, Handy RD (2007) Toxicity of titanium dioxide nanoparticles to rainbow trout, (Oncorhynchus mykiss): gill injury, oxidative stress, and other physiological effects. Aquat Toxicol 84:415-430

Fraser TWK, Reinardy HC, Shaw BJ, Henry TB, Handy RD (2011) Dietary toxicity of single-walled carbon nanotubes and fullerenes $\left(\mathrm{C}_{60}\right)$ in rainbow trout (Oncorhynchus mykiss). Nanotoxicology 5:98-108

Gellert G, Heinrichsdorff J (2001) Effect of age on the susceptibility of zebrafish eggs to industrial wastewater. Water Res 35:3754-3757

Griffitt RJ, Weil R, Hyndman KA, Denslow ND, Powers K, Taylor D, Barber DS (2007) Exposure to copper nanoparticles causes gill injury and acute lethality in zebrafish (Danio rerio). Environ Sci Technol 41:8178-8186

Griffitt RJ, Luo J, Gao J, Bonzongo JC, Barber DS (2008) Effects of particle composition and species on toxicity of metallic nanomaterials in aquatic organisms. Environ Toxicol Chem 27:1972-1978

Groh KJ, Carvalho RN, Chipman JK, Denslow ND, Halder M, Murphy CA, Roelofs D, Rolaki A, Schirmer K, Watanabe KH (2015) Development and application of the adverse outcome pathway framework for understanding and predicting chronic toxicity: II. A focus on growth impairment in fish. Chemosphere 120:778-792

Guadagnolo CM, Brauner CJ, Wood CM (2001) Chronic effects of silver exposure on ion levels, survival, and silver distribution within developing rainbow trout (Oncorhynchus mykiss) embryos. Environ Toxicol Chem 20:553-560

Halder M, Léonard M, Iguchi T, Oris JT, Ryder K, Belanger SE, Braunbeck TA, Embry MR, Whale G, Norberg-King T, Lillicrap A (2010) Regulatory aspects on the use of fish embryos in environmental toxicology. Integr Environ Assess Manag $6: 484-491$
Handy RD, Shaw BJ (2007) Ecotoxicity of nanomaterials to fish: challenges for ecotoxicity testing. Integr Environ Assess Manag 3:458-460

Handy RD, Sims DW, Giles A, Campbell HA, Musonda MM (1999) Metabolic trade-off between locomotion and detoxification for maintenance of blood chemistry and growth parameters by rainbow trout (Oncorhynchus mykiss) during chronic dietary exposure to copper. Aquat Toxicol 47:23-41

Handy RD, von der Kammer F, Lead JR, Hassellöv M, Owen R, Crane M (2008) The ecotoxicology and chemistry of manufactured nanoparticles. Ecotoxicology 17:287-314

Handy RD, Al-Bairuty G, Al-Jubory A, Ramsden CS, Boyle D, Shaw BJ, Henry TB (2011) Effects of manufactured nanomaterials on fishes: a target organ and body systems physiology approach. J Fish Biol 79:821-853

Handy RD, van den Brink N, Chappell M, Mühling M, Behra R, Dušinská M, Simpson P, Ahtiainen J, Jha AN, Seiter J, Bednar A, Kennedy A, Fernandes TF, Riediker M (2012a) Practical considerations for conducting ecotoxicity test methods with manufactured nanomaterials: what have we learnt so far? Ecotoxicology 21:933-972

Handy RD, Cornelis G, Fernandes T, Tsyusko O, Decho A, SaboAttwood T, Metcalfe C, Steevens JA, Klaine SJ, Koelmans AA, Horne N (2012b) Ecotoxicity test methods for engineered nanomaterials: practical experiences and recommendations from the bench. Environ Toxicol Chem 31:15-31

Henn K, Braunbeck T (2011) Dechorionation as a tool to improve the fish embryo toxicity test (FET) with the zebrafish (Danio rerio). Comp Biochem Physiol C 153:91-98

Holeton GF, Randall DJ (1967) The effect of hypoxia upon the partial pressure of gases in the blood and water afferent and efferent to the gills of rainbow trout. J Exp Biol 46:317-327

Jager T (2012) Bad habits die hard: the NOEC's persistence reflects poorly on ecotoxicology. Environ Toxicol Chem 31:228-229

Johnson A, Carew E, Sloman KA (2007) The effects of copper on the morphological and functional development of zebrafish embryos. Aquat Toxicol 84:431-438

Kimmel CB, Ballard WW, Kimmel SR, Ullmann B, Schilling TF (1995) Stages of embryonic development of the zebrafish. Dev Dyn 203:25-310

Klaine SJ, Alvarez PJJ, Batley GE, Fernandes TF, Handy RD, Lyon DY, Mahendra S, McLaughlin MJ, Lead JR (2008) Nanomaterials in the environment: behavior, fate, bioavailability, and effects. Environ Toxicol Chem 27:1825-1851

Klaine SJ, Koelmans AA, Horne N, Carley S, Handy RD, Kapustka L, Nowack B, von der Kammer F (2012) Paradigms to assess the environmental impact of manufactured nanomaterials. Environ Toxicol Chem 31:3-14

Klein CL, Comero S, Stahlmecke B, Romazanov J, Kuhlbusch TAJ, Van Doren E, De Temmerman P-J, Mast J, Wick P, Krug H, Locoro G, Hund-Rinke K, Kördel W, Friedrichs S, Maier G, Werner J, Lingsinger Th, Gawlik BM (2011) NM-series of representative manufactured nanomaterials NM-300 silver characterisation, stability, homogeneity. JRC Scientific and Technical Reports

Knöbel M, Busser FJM, Rico-Rico A, Kramer NI, Hermens JLM, Hafner C, Tanneberger K, Schirmer K, Scholz S (2012) Predicting adult fish acute lethality with the zebrafish embryo: Relevance of test duration, endpoints, compound properties, and exposure concentration analysis. Environ Sci Technol 46: 9690-9700

Kwok KWH, Auffan M, Badireddy AR, Nelson CM, Wiesner MR, Chilkoti A, Liu J, Marinakos SM, Hinton DE (2012) Uptake of silver nanoparticles and toxicity to early life stages of Japanese medaka (Oryzias latipes): effect of coating materials. Aquat Toxicol 120-121:59-66 
Laale HW (1977) The biology and use of zebrafish, Brachydanio rerio in fisheries research. A literature review. J Fish Biol 10:121-173

Landis WG, Chapman PM (2011) Well past time to stop using NOELs and LOELs. Integr Environ Assess Manag 7:vi-viii

Laskowski R (1995) Some good reasons to ban the use of NOEC, LOEC and related concepts in ecotoxicology. Oikos 73:140-144

Lee KJ, Nallathamby PD, Browning LM, Osgood CJ, Xu X-HN (2007) In vivo imaging of transport and biocompatibility of single silver nanoparticles in early development of zebrafish embryos. ACS Nano 1:133-143

Lee B, Duong CN, Cho J, Lee J, Kim K, Seo Y, Kim P, Choi K, Yoon J (2012) Toxicity of citrate-capped silver nanoparticles in common carp (Cyprinus carpio). J Biomed Biotechnol vol 2012, Article ID 262670

Liu XT, Mu XY, Wu XL, Meng LX, Guan WB, Ma YQ, Sun H, Wang CJ, Li XF (2014) Toxicity of multi-walled carbon nanotubes, graphene oxide, and reduced graphene oxide to zebrafish embryos. Biomed Environ Sci 27:676-683

Ma H, Diamond SA (2013) Phototoxicity of $\mathrm{TiO}_{2}$ nanoparticles to zebrafish (Danio rerio) is dependent on life stage. Environ Toxicol Chem 2:2139-2143

MacCormack TJ, Goss GG, Handy RD (2014) Emerging threats to fishes: Engineered organic nanomaterials. In: Tierney KB, Farrell AP, Brauner CJ (eds) Organic chemical toxicology of fishes. Fish physiology, vol 33. Academic Press, San Diego, pp 439-479

McKim JM, Eaton JG, Holcombe GW (1978) Metal toxicity to embryos and larvae of eight species of freshwater fish-II: copper. Bull Environ Contam Toxicol 19:608-616

Menke AL, Spitsbergen JM, Wolterbeek APM, Woutersen RA (2011) Normal anatomy and histology of the adult zebrafish. Toxicol Pathol 39:759-775

Mitrano DM, Ranville JF, Bednar A, Kazor K, Hering AS, Higgins CP (2014) Tracking dissolution of silver nanoparticles at environmentally relevant concentrations in laboratory, natural, and processed waters using single particle ICP-MS (spICP-MS). Environ Sci Nano 1:248-259

Mizell M, Romig ES (1997) The aquatic vertebrate embryo as a sentinel for toxins: zebrafish embryo dechorionation and perivitelline space microinjection. Int J Dev Biol 41:411-423

Müller UK (2008) Swimming and muscle. In: Finn RN, Kapoor BG (eds) Fish larval physiology. Science Publishers, Enfield, pp 523-549

OECD (1992a) Test no. 210: test no. 210. OECD guidelines for testing of chemicals. fish, early-life stage test. The Organisation for Economic Co-operation and Development

OECD (1992b) Test no. 203. Fish, acute toxicity test. OECD guidelines for the testing of chemicals. http://www.keepeek.com/Digital-Asset-Management/oecd/environment/ test-no-203-fish-acute-toxicity-test_9789264069961-en\#page6

OECD (1998) Test no. 203. Fish, short-term toxicity test on embryo and sac-fry stages. OECD guidelines for the testing of chemicals. http://www.oecd-ilibrary.org/docserver/ download/9721201e.pdf?expires $=1445776299 \& \mathrm{id}=\mathrm{id} \&$ accna $\mathrm{me}=$ guest $\&$ checksum $=1$ DEEEB7D378004012F09C90D548E $726 \mathrm{D}$

OECD (2000) Guidance document on aquatic toxicity testing of difficult substances and mixtures. OECD series on testing and assessment number 23. http://www.oecd.org/officialdocuments/ publicdisplaydocumentpdf $/$ ?cote $=$ env $/ \mathrm{jm} / \mathrm{mono}(2000) 6 \&$ docla nguage $=$ en

OECD (2012) Guidance on sample preparation and dosimetry for the safety testing of manufactured nanomaterials. Series on the safety of manufactured nanomaterials no. 36. http://www.oecd. org/officialdocuments/publicdisplaydocumentpdf/?cote=env/ $\mathrm{jm} / \mathrm{mono}(2012) 40 \&$ doclanguage $=\mathrm{en}$
OECD (2013) Test no. 210: fish, early-life stage toxicity test. OECD guidelines for the testing of chemicals, Section 2. http://www. oecd-ilibrary.org/environment/test-no-210-fish-early-life stagetoxicity-test_9789264203785-en. OECD Publishing

Oris JT, Belanger SE, Bailer AJ (2012) Baseline characteristics and statistical implications for the OECD 210 fish early-life stage chronic toxicity test. Environ Toxicol Chem 31:370-376

Parichy DM, Elizondo MR, Mills MG, Gordon TN, Engeszer RE (2009) Normal table of postembryonic zebrafish development: staging by externally visible anatomy of the living fish. Dev Dyn 238:2975-3015

Petersen EJ, Henry TB, Zhao J, MacCuspie RI, Kirschling TL, Dobrovolskaia MA, Hackley V, Xing B, White JC (2014) Identification and avoidance of potential artifacts and misinterpretations in nanomaterial ecotoxicity measurements. Environ Sci Technol 48:4226-4246

Petersen EJ, Diamond SA, Kennedy AJ, Goss GG, Ho K, Lead J, Hanna SK, Hartmann NB, Hund-Rinke K, Mader B, Manier N, Pandard P, Salinas ER, Sayre P (2015) Adapting OECD aquatic toxicity tests for use with manufactured nanomaterials: key issues and consensus recommendations. Environ Sci Technol 49:9532-9547

Ramsden CS, Smith TJ, Shaw BJ, Handy RD (2009) Dietary exposure to titanium dioxide nanoparticles in rainbow trout, (Oncorhynchus mykiss): no effect on growth, but subtle biochemical disturbances in the brain. Ecotoxicology 18:939-951

Ramsden CS, Henry TB, Handy RD (2013) Sub-lethal effects of titanium dioxide nanoparticles on the physiology and reproduction of zebrafish. Aquat Toxicol 126:404-413

Rand GM, Wells PG, McCarty LS (1995) Introduction to aquatic toxicology. In: Rand GH (ed) Fundamentals of aquatic toxicology, 2nd edn. CRC Press, Boca Raton, pp 3-67

Ranville J, Montano M (2015) Physicochemical characterizationsize distributions. In: Baalousha M, Lead JR (eds) Characterization of nanomaterials in complex environmental and biological media. Frontiers of nanoscience, vol 8. Elsevier, Amsterdam, p 320

Rasmussen K, Mast J, De Temmerman P-J, Verleysen E, Waegeneers N, Van Steen F, Pizzolon JC, De Temmerman L, Van Doren E, Jensen KA, Birkedal R, Levin M, Nielsen SH, Koponen IK, Clausen PA, Kofoed-Sørensen V, Kembouche Y, Thieriet N, Spalla O, Guiot C, Rousset D, Witschger O, Bau S, Bianchi B, Motzkus C, Shivachev B, Dimowa L, Nikolova R, Nihtianova D, Tarassov M, Petrov O, Bakardjieva S, Gilliland D, Pianella F, Ceccone G, Spampinato V, Cotogno G, Gibson N, Gaillard C, Mech A (2014a) Titanium dioxide, NM-100, NM-101, NM-102, NM-103, NM-104, NM-105: characterisation and physico-chemical properties, JRC repository: NM-series of representative manufactured nanomaterials. JRC Science and Policy Reports

Rasmussen K, Mast J, De Temmerman P-J, Verleysen E, Waegeneers N, Van Steen F, Pizzolon JC, De Temmerman L, Van Doren E, Jensen KA, Birkedal R, Clausen PA, Kembouche Y, Thieriet N, Spalla O, Guiot C, Rousset D, Witschger O, Bau S, Bianchi B, Shivachev B, Dimowa L, Nikolova R, Nihtianova D, Tarassov M, Petrov O, Bakardjieva S, Motzkus C, Labarraque G, Oster C, Cotogno G, Gailliard C (2014b) Multi-walled carbon nanotubes, NM-400, NM-401, NM-402, NM-403: characterisation and physico-chemical properties. JRC repository: NM-series of representative manufactured nanomaterials. JRC Science and Policy Reports

Rawson DM, Zhang T, Kalicharan D, Jongebloed WL (2000) Field emission scanning electron microscopy and transmission electron microscopy studies of the chorion, plasma membrane and syncytial layers of the gastrula-stage embryo of the zebrafish Brachydanio rerio: a consideration of the structural and 
functional relationships with respect to cryoprotectant penetration. Aquac Res 3:325-336

Ribeiro F, Gallego-Urrea JA, Jurkschat K, Crossley A, Hassellöv M, Taylor C, Soares AMVM, Loureiro S (2014) Silver nanoparticles and silver nitrate induce high toxicity to Pseudokirchneriella subcapitata, Daphnia magna and Danio rerio. Sci Total Environ 466-467:232-241

Rojo I, Uriate M, Obieta I, Bustero I, Egizabal A, Pardo MA, de Ilárduya M (2007) Toxicogenomics study of nanomaterials on the model organism zebrafish. In: Technical proceedings of the 2007 NSTI nanotechnology conference and trade show, vol 2, pp 655-658

Rombough PJ (1985) The influence of the zona radiata on the toxicities of zinc, lead, mercury, copper, and silver ions to embryos of steelhead trout Salmo gairdneri. Comp Biochem Physiol C $82: 115-117$

Sánchez-Bayo F (2012) Should we forget NOECs? Integr Environ Assess Manag 8:564-565

Schilling TF (2002) The morphology of larval and adult zebrafish. In: Nusslein-Volhard C, Ralf-Dahm R (eds) Zebrafish (practical approach series). Oxford University Press, Oxford, pp 59-94

Schlenk D, Handy R, Steinert S, Depledge MH, Benson W (2008) Biomarkers. In: Di Giulio RT, Hinton DE (eds) The toxicology of fishes. CRC Press, Boca Raton, p 1071

Schwab F, Bucheli TD, Lukhele LP, Magrez A, Nowack B, Sigg L, Knauer K (2011) Are carbon nanotube effects on green algae caused by shading and agglomeration? Environ Sci Technol 45:6136-6144

Shaw BJ, Al-Bairuty G, Handy RD (2012) Effects of waterborne copper nanoparticles and copper sulphate on rainbow trout, (Oncorhynchus mykiss): physiology and accumulation. Aquat Toxicol 116-117:90-101

Shaw BJ, Ramsden CS, Turner A, Handy RD (2013) A simplified method for determining titanium from $\mathrm{TiO}_{2}$ nanoparticles in fish tissue with a concomitant multi-element analysis. Chemosphere 92:1136-1144

Simonet BM, Valcárcel M (2009) Monitoring nanoparticles in the environment. Anal Bioanal Chem 393:17-21
Skalski JR (1981) Statistical inconsistencies in the use of noobserved-effect-levels in toxicity testing. In: Branson DR, Dickson KL (eds) Aquatic toxicology and hazard evaluation. American Society for Testing and Materials, Philadelphia, pp 337-387

Tiede K, Boxall ABA, Tear SP, Lewis J, David H, Hassellöv M (2008) Detection and characterization of engineered nanoparticles in food and the environment. Food Addit Contam 25:795-821

Truong L, Saili KS, Miller JM, Hutchinson JE, Tanguay RL (2012) Persistent adult zebrafish behavioral deficits results from acute embryonic exposure to gold nanoparticles. Comp Biochem Physiol C 155:269-274

Velasco-Santamaría YM, Handy RD, Sloman KA (2011) Endosulfan affects health variables in adult zebrafish (Danio rerio) and induces alterations in larvae development. Comp Biochem Physiol C Toxicol Pharmacol 153:372-380

von der Kammer F, Ferguson PL, Holden PA, Masion A, Rogers KR, Klaine SJ, Koelmans AA, Horne N, Unrine JM (2012) Analysis of engineered nanomaterials in complex matrices (environment and biota): general considerations and conceptual case studies. Environ Toxicol Chem 31:32-49

Warne MSJ, van Dam R (2008) NOEC and LOEC data should no longer be generated or used. Australas J Ecotoxicol 14:1-5

Welsh PG, Lipton J, Mebane CA, Marr JCA (2008) Influence of flowthrough and renewal exposures on the toxicity of copper to rainbow trout. Ecotoxicol Environ Saf 69:199-208

Witeska M, Sarnowski P, Ługowska K, Kowal E (2014) The effects of cadmium and copper on embryonic and larval development of ide Leuciscus idus L. Fish Physiol Biochem 40:151-163

Zhang Y, Chen Y, Paul Westerhoff P, Crittenden J (2009) Impact of natural organic matter and divalent cations on the stability of aqueous nanoparticles. Water Res 43:4249-4257

Zhu X, Zhu L, Duan Z, Qi R, Li Y, Lang Y (2008) Comparative toxicity of several metal oxide nanoparticle aqueous suspensions to Zebrafish (Danio rerio) early developmental stage. J Environ Sci Health A 43:278-284

Zhu B, Liu G-L, Ling F, Song L-S, Wang G-X (2015) Development toxicity of functionalized single-walled carbon nanotubes on rare minnow embryos and larvae. Nanotoxicology 9:579-590 